\title{
A Phase Locking Perspective on Rossby Wave Amplification and Atmospheric Blocking Downstream of Recurving Western North Pacific Tropical Cyclones ${ }^{\mathscr{O}}$
}

\author{
JACOPO RIBOLDI ${ }^{\mathrm{a}}$ AND CHRISTIAN M. GRAMS ${ }^{\mathrm{b}}$ \\ Institute for Atmospheric and Climate Science, ETH Zurich, Zurich, Switzerland \\ MICHAEL RIEMER \\ Institut für Physik der Atmosphäre, Johannes Gutenberg-Universität Mainz, Mainz, Germany \\ Heather M. Archambault \\ NOAA/Geophysical Fluid Dynamics Laboratory, Princeton, New Jersey
}

(Manuscript received 2 August 2018, in final form 20 November 2018)

\begin{abstract}
The extratropical transition (ET) of tropical cyclones (TCs) can significantly influence the evolution of the midlatitude flow. However, the interaction between recurving TCs and upstream upper-level troughs features a large and partly unexplained case-to-case variability. In this study, a synoptic, feature-based climatology of TC-trough interactions is constructed to discriminate recurving TCs that interact with decelerating and accelerating troughs. Upper-level troughs reducing their eastward propagation speed during the interaction with recurving TCs exhibit phase locking with lower-level temperature anomalies and are linked to pronounced downstream Rossby wave amplification. Conversely, accelerating troughs do not exhibit phase locking and are associated with a nonsignificant downstream impact. Irrotational outflow near the tropopause associated with latent heat release in regions of heavy precipitation near the transitioning storm can promote phase locking (via enhancement of trough deceleration) and further enhance the downstream impact (via advection of air with low potential vorticity in the direction of the waveguide). These different impacts affect the probability of atmospheric blocking at the end of the Pacific storm track, which is generally higher if a TC-trough interaction occurs in the western North Pacific. Blocking in the eastern North Pacific is up to 3 times more likely than climatology if an interaction between a TC and a decelerating trough occurs upstream, whereas no statistical deviation with respect to climatology is observed for accelerating troughs. The outlined results support the hypothesis that differences in phase locking can explain the observed variability in the downstream impact of ET.
\end{abstract}

\section{Introduction}

Recurving tropical cyclones (TCs) undergoing extratropical transition (ET) are known to affect the extratropical circulation by altering the amplification, the

Supplemental information related to this paper is available at the Journals Online website: https://doi.org/10.1175/MWR-D-18-0271.s1.

\footnotetext{
${ }^{a}$ Current affiliation: Laboratoire de Météorologie Dynamique, École Normale Supérieure, Paris, France.

${ }^{\mathrm{b}}$ Current affiliation: Institute of Meteorology and Climate Research (IMK-TRO), Karlsruhe Institute of Technology, Karlsruhe, Germany.
}

Corresponding author: Jacopo Riboldi, jacopo.riboldi@env.ethz.ch propagation, and the breaking of midlatitude Rossby wave packets (RWPs; see Jones et al. 2003; Wirth et al. 2018; Keller et al. 2019). However, the impact of ET on the waveguide exhibits a very large case-to-case variability (e.g., McTaggart-Cowan et al. 2001, 2004; AgustíPanareda et al. 2005; Agustí-Panareda 2008; Harr and Dea 2009; Keller et al. 2014; Pantillon et al. 2016). Both the extratropical reintensification of the recurving TC and the evolution of RWPs downstream of ET were found to be very dependent on the relative position (i.e., the "phasing") between the TC itself and the upper-level positive PV anomalies (troughs) propagating along the midlatitude waveguide (Klein et al. 2000; Harr et al. 2000; Klein et al. 2002; Ritchie and Elsberry 2007; Pantillon et al. 2013; Grams et al. 2013a; Riemer and Jones 2014). 
The present study aims to understand the dynamical processes that relate phasing during ET to downstream RWP amplification and atmospheric blocking.

In general, the presence of an upper-level trough upstream of the recurving TC favors a strong impact of ET on the downstream flow (Archambault et al. 2015; Torn and Hakim 2015; Quinting and Jones 2016). Sensitivity studies highlighted a positive correlation between the time spent by the TC ahead of such a trough and the strength of the downstream impact (Scheck et al. 2011a,b; Grams et al. 2013a; Riemer and Jones 2014). This is most likely due to an enhanced potential for reintensification of the transitioning TC as an extratropical cyclone. Ahead of a trough, the storm may be located in a region of positive vorticity advection and forcing for ascent in the vicinity of a low-level baroclinic zone, a setup conducive to Petterssen-Smebye Type-B cyclogenesis (Klein et al. 2002; Ritchie and Elsberry 2003). The mutual reinforcing of upper-level PV anomalies and lower-level temperature anomalies was also summarized in the "phase locking" paradigm of baroclinic instability in the seminal work by Hoskins et al. (1985): this perspective will be adopted in the present study to physically explain the importance of phasing.

Another aspect highlighted in previous research is the importance of latent heat release in shaping the evolution of ET and its downstream impact. Moist and unstable tropical air masses, which surround recurving TCs, ascend in the vicinity of the jet stream, forming clouds and precipitation and leading to strong latent heat release (Grams et al. 2013b; Grams and Archambault 2016). The associated patterns of potential vorticity (PV) creation and destruction can influence the large-scale flow by enhancing low-level cyclonic circulations (Stoelinga 1996; Čampa and Wernli 2012; Binder et al. 2016; Crezee et al. 2017) and upper-level anticyclonic circulations (Hoskins et al. 1985; Davis et al. 1993; Pomroy and Thorpe 2000; Joos and Wernli 2012). This second effect is most evident during ET, as it can significantly contribute to the genesis of a negative PV anomaly at the waveguide (ridge) downstream of the TC. The building of such a ridge is shaped by the action of the cyclonic and anticyclonic circulations of the transitioning TC and by the irrotational, low-PV outflow due to strong and persistent latent heat release (Atallah and Bosart 2003; Riemer et al. 2008; Riemer and Jones 2010; Hodyss and Hendricks 2010; Grams et al. 2013b; Archambault et al. 2013, 2015).

A second effect of latent heat release during ET is the thinning and the meridional elongation of the trough upstream of the transitioning TC and the hindering of its eastward propagation (Pantillon et al. 2013; Riemer and Jones 2014; Archambault et al. 2015). Variations in trough speed can be explained by the amplification of the downstream ridge, which opposes the eastward propagation of the trough itself as it propagates against the background flow. As a result, the transitioning TC can remain ahead of a decelerating trough for a longer time, favoring phase locking and enhancing ridge building and downstream impact. In addition, latent heat release in clouds can diminish tropospheric static stability and increase the Rossby penetration depth, facilitating the onset and increasing the strength of phase locking (Hoskins et al. 1985). The simultaneous, two-way interaction of the circulations induced by latent heat release, upper-level PV anomalies, and lowerlevel temperature anomalies during ET has also been described as a "synergistic interaction" (Bosart and Lackmann 1995; Quinting and Jones 2016). A first objective of the current study is the systematical investigation of this interaction and of its role in modulating the downstream impact of ET.

As discussed previously, ET can lead to RWP amplification, and blocking anticyclones are a typical atmospheric feature occurring in meridionally amplified flow (e.g., Rex 1950; Altenhoff et al. 2008; Masato et al. 2012). A documented example is the upper-level warm anomaly associated with Hurricane Katrina (2005), which evolved into a block over the North Atlantic despite the missing reintensification of the storm as an extratropical cyclone during ET (McTaggart-Cowan et al. 2007a,b). Atmospheric blocking can also pave the way to extreme events: Barton et al. (2016) documented how a series of three TCs (Florence, Helene, and Leslie), recurving in the North Atlantic between September and October 2000, led to the continuous invigoration of atmospheric blocks over the North Atlantic and to repeated Rossby wave breaking over western Europe associated with extreme flooding over southern Switzerland and northern Italy. It has been hypothesized that a link exists between ET in the western North Pacific and enhanced blocking activity over western North America during the months of August, September, and October (Small et al. 2014). The second objective of this study is testing this hypothesis, via a targeted assessment of the relationship between ET and blocking frequency anomalies in the North Pacific.

In synthesis, the present study proposes a climatological investigation of phasing in the context of recurving TCs interacting with upper-level troughs, with the aim to understand how small differences in phasing can result in big differences in RWP amplitude and atmospheric blocking downstream of ET. This analysis will be carried out for a subset of TCs that occurred between 1979 and 2013 in the western North Pacific. A feature-based approach is adopted: the analysis will be carried out in a frame of reference moving with the upstream troughs, with the aim to characterize their 
degree of phasing with the TC and to highlight the synergistic interaction between adiabatic and diabatic processes during ET. The employed trough tracking, together with other relevant diagnostics, is discussed in section 2. A description of TC-trough interactions in terms of interplay between adiabatic and diabatic processes and of their effect on atmospheric blocking constitutes the main results of this study (section 3). Finally, conclusions are summarized in section 4 .

\section{Data and methodology}

\section{a. Data}

ECMWF interim reanalysis (ERA-Interim; Dee et al. 2011) data interpolated on isentropic levels, at $1^{\circ} \times 1^{\circ}$ horizontal resolution and 6-hourly temporal resolution, are employed to characterize and track upper-level troughs. The IBTrACS dataset (Knapp et al. 2010) provides information about recurving TCs in the western North Pacific between 1979 and 2013: this basin is chosen as it features the highest absolute number of recurving TCs among all basins (e.g., Knaff 2009). Recurvature is defined as a change in the direction of a northward-moving TC at the westernmost point of its track, where the TC stops heading westward and starts moving eastward: intensity at recurvature time must be at least $17 \mathrm{~m} \mathrm{~s}^{-1}$ and the storm classified as extratropical at the end of its life cycle (as in Archambault et al. 2013). In contrast to Archambault et al. (2013), TCs that undergo recurvature above $45^{\circ} \mathrm{N}$ are not included, whereas TCs that track in a loop are included (as in Riboldi et al. 2018).

The 215 TCs recurving during the months of August, September, and October (ASO) are analyzed. The vertically averaged negative PV advection by the irrotational wind in the upper troposphere $(345-355-\mathrm{K}$ isentropic layer) is then employed to quantify and locate the interaction of TCs with the waveguide, similarly to Archambault et al. (2015). The time of minimum PV advection by the irrotational wind, searched in a $30^{\circ} \times$ $15^{\circ}$ search box north of the TC, is defined as the maximum interaction time $t_{\mathrm{ET}}$. Note that $t_{\mathrm{ET}}$ does not necessarily coincide with objective definitions of ET completion time from other studies, which focused more on the structure of the transitioning storm rather than on its degree of interaction with an upstream trough (e.g., Evans and Hart 2003; Studholme et al. 2015). The nearest trough upstream of the TC at $t_{\mathrm{ET}}$ is identified and tracked. All the cases have been manually inspected to avoid two TCs recurving at the same time also having the same maximum interaction point and to make sure that the correct upstream trough at $t_{\mathrm{ET}}$ is tracked.

\section{b. Trough tracking}

A tracking algorithm is implemented to diagnose the zonal propagation of upper-level troughs. The algorithm stems from the one described by Berry et al. (2007) to track waves propagating along the African easterly jet. Two modifications were implemented to make the tracking of midlatitude upper-level troughs possible (Table 1). First, the algorithm is applied on isentropic surfaces to obtain the vertically averaged $(315-355 \mathrm{~K})$ nondivergent component of the wind $\mathbf{V}_{\psi}=\left(u_{\psi}, v_{\psi}\right)$, using a successive overrelaxation method. Using the same method, the signature of the TC is removed at each time step from the nondivergent wind field by inverting the vorticity enclosed in a circle of radius $R=600 \mathrm{~km}$, centered at TC location in IBTrACS. Second, the algorithm does not consider the axis of the troughs but evaluates socalled "trough objects," contiguous regions of cyclonic vorticity advection (CVA) larger than $10^{-10} \mathrm{~s}^{-2}$, where

$$
\mathrm{CVA}=-\mathbf{V}_{\psi} \cdot \nabla \zeta_{\text {curv }},
$$

and $\zeta_{\text {curv }}$ is the component of vorticity due to the curvature of the flow only. Finally, unlike African easterly waves, midlatitude troughs propagate along the westerly jet stream, and therefore trough objects must be embedded in a region of positive zonal wind (see Table 1). The described trough objects are usually located near the eastern side of a trough and are easier to identify and track than the trough axis. For further details about the original algorithm, the reader is referred to Berry et al. (2007).

It is assumed that the closest trough in the vicinity of the TC at $t_{\mathrm{ET}}$ is interacting with the TC itself and therefore should be tracked. Information about the location of the trough is collapsed in a single point, called the trough center of mass $(\mathrm{CM})$. The location of the trough $\mathrm{CM}$ is initially determined at $t_{\mathrm{ET}}-6 \mathrm{~h}, t_{\mathrm{ET}}$, and $t_{\mathrm{ET}}+6 \mathrm{~h}$ in a fixed $20^{\circ} \times 20^{\circ}$ search box centered at the grid point of minimum PV advection by the irrotational wind at $t_{\mathrm{ET}}$, denoted as "location of maximum interaction" (Figs. 1c-e).

Every trough object $T_{k}, k=1, \ldots, K$, extending over $J_{k}$ connected grid points and occupying an area of at least $25000 \mathrm{~km}^{2}$ is considered, and it is assigned a magnitude $I_{k}=\sum_{j_{k}=1}^{J_{k}} \mathrm{CVA}_{j_{k}}^{2}$ that corresponds to its integrated value of squared CVA, and a center point $\mathbf{C}_{k}$ of coordinates

$$
\begin{aligned}
\mathbf{C}_{k} & =\left(x_{C_{k}}, y_{C_{k}}\right) \\
& =\frac{1}{\sum_{j_{k}=1}^{J_{k}} \mathrm{CVA}_{j_{k}}}\left(\sum_{j_{k}=1}^{J_{k}} x_{j_{k}} \mathrm{CVA}_{j_{k}}, \sum_{j_{k}=1}^{J_{k}} y_{j_{k}} \mathrm{CVA}_{j_{k}}\right),
\end{aligned}
$$


TABLE 1. Thresholds adopted to define trough objects.

\begin{tabular}{|c|c|c|c|}
\hline No. & Condition & Description & $\begin{array}{l}\text { Different } \\
\text { from Berry } \\
\text { et al. (2007) }\end{array}$ \\
\hline 1 & $\mathrm{CVA}>10^{-10} \mathrm{~s}^{-2}$ & $\begin{array}{l}\text { Diagnostics used to } \\
\text { identify trough } \\
\text { objects. }\end{array}$ & Yes \\
\hline 2 & $\zeta_{\text {curv }}>0.5 \times 10^{-5} \mathrm{~s}^{-1}$ & $\begin{array}{l}\text { Exclude ridges and } \\
\text { weak troughs } \\
\text { (in the Northern } \\
\text { Hemisphere). }\end{array}$ & \\
\hline 3 & $-\mathbf{V}_{\psi} \cdot \nabla \mathrm{CVA}>0 \mathrm{~s}^{-3}$ & $\begin{array}{l}\text { Removes areas } \\
\text { embedded in } \\
\text { strongly curved flow. }\end{array}$ & \\
\hline 4 & $u_{\psi}>0 \mathrm{~m} \mathrm{~s}^{-1}$ & $\begin{array}{l}\text { Trough objects must } \\
\text { propagate in } \\
\text { westerly flow. }\end{array}$ & Yes \\
\hline
\end{tabular}

where $x$ and $y$ stand for longitude and (cosine weighted) latitude, respectively. Given that a trough can be composed by several neighboring trough objects, the position of the trough $\mathrm{CM}$ is obtained from a weighted average across the $N$ grid points of the search box and has coordinates

$$
x_{\mathrm{CM}}=\frac{\sum_{j=1}^{N} x_{j} w_{j}}{\sum_{j=1}^{N} w_{j}}, \quad y_{\mathrm{CM}}=\frac{\sum_{j=1}^{N} y_{j} w_{j}}{\sum_{j=1}^{N} w_{j}},
$$

with weights $w_{j}$ for each trough object

$$
w_{j}=\left\{\begin{array}{lll}
\frac{I_{k}}{d_{k}} & \text { if } & j \in T_{k} \\
0 & \text { if } & j \notin T_{k}
\end{array},\right.
$$

where $d_{k}$ is the distance between each trough object center $\mathbf{C}_{k}$ and the center of the search box ( $d_{k}$ cannot be less than $1 \mathrm{~km}$ ).

Away from $t_{\mathrm{ET}}$, the position of the search box is not anymore fixed but centered at the expected position of trough $\mathrm{CM}$, linearly extrapolated from the speed of the trough $\mathrm{CM}$ at the preceding time step (Figs. 1a,b,f,g). After the initial localization of the trough $\mathrm{CM}$, the size of the search box is slightly reduced $\left(16^{\circ} \times 20^{\circ}\right)$ to minimize errors resulting from other, unrelated trough objects entering the search box during the tracking. The trough CM is tracked until genesis/dissipation: tracking is interrupted if it fails for two consecutive time step (i.e., if it is not possible to identify a trough object broader than $25000 \mathrm{~km}^{2}$ in the considered search box).

An upper-level trough could be identified and tracked for 213 out of 215 recurving TCs: the result of this procedure is 213 time series of trough CM positions. The zonal component of trough CM speed $c$ is obtained using forward finite differences in longitude across the considered time steps, followed by a 48-h moving average. For $N_{\mathrm{ALL}}=195 \mathrm{TCs}, c$ could be computed between $t_{\mathrm{ET}}-48 \mathrm{~h}$ and $t_{\mathrm{ET}}+12 \mathrm{~h}$, and this constitutes the full set of TC-trough interactions analyzed in this study (the ALL subset). The two time steps mark, on average, the time when trough deceleration begins and the time of minimum trough speed, respectively (see Fig. S1 in the online supplemental material).

\section{c. Downstream impact diagnostics}

Flow amplification over the North Pacific downstream of TC-trough interactions is evaluated using the metric of Zimin et al. (2006). This metric evaluates the amplitude of RWPs, detected using a Hilbert transform of the 250-hPa wind. Only the wind component that is orthogonal to a local approximation of the background flow (i.e., a closed streamline spanning the Northern Hemisphere in the 20-day moving average of the wind field) is employed in the computation. This orthogonal wind component is filtered using a Fourier transform to retain the positive hemispheric wavenumbers $5<k<15$ : such wavenumbers correspond to a broad range of synoptic-scale eddies. The modulus of the filtered inverse Fourier transform provides the amplitude $A$ of the envelope of the identified packet. Two regions overlapping near the date line are defined: one covering the western portion of the North Pacific $\left(25^{\circ}-\right.$ $75^{\circ} \mathrm{N}, 100^{\circ} \mathrm{E}-170^{\circ} \mathrm{W}$ ), and the other one covering the eastern portion $\left(25^{\circ}-75^{\circ} \mathrm{N}, 170^{\circ} \mathrm{E}-100^{\circ} \mathrm{W}\right)$. The natural $\operatorname{logarithm} \gamma=\ln \bar{A}$ of the spatially averaged RWP amplitude $\bar{A}$ in each region is employed as a measure of RWP amplitude, because the distribution of $\bar{A}$ is approximately lognormal and therefore $\gamma$ follows a Gaussian distribution with a well-defined value of standard deviation. After having computed the climatological mean and the standard deviation of $\gamma$ at each time step between 1979 and 2013, a 30-day running average is applied, and the resulting smoothed time series of mean $\left(\bar{\mu}_{\gamma}\right)$ and standard deviation $\left(\bar{\sigma}_{\gamma}\right)$ are used as reference for the computation of standardized anomalies (i.e., in units of standard deviations) of RWP amplitude:

$$
\mathrm{ANOM}_{W}=\frac{\gamma_{W}-\bar{\mu}_{\gamma_{W}}}{\bar{\sigma}_{\gamma_{W}}} \quad \operatorname{ANOM}_{E}=\frac{\gamma_{E}-\bar{\mu}_{\gamma_{E}}}{\bar{\sigma}_{\gamma_{E}}},
$$

where the subscripts $\mathrm{W}$ and $\mathrm{E}$ refer, respectively, to the west and east Pacific regions. Statistically significant anomalies are defined in each region with respect to a null distribution of medians of 2500 randomly selected subsets of ANOM values. To build each subset, an ANOM value is randomly selected in a 15-day time 
(a) $25 / 12$

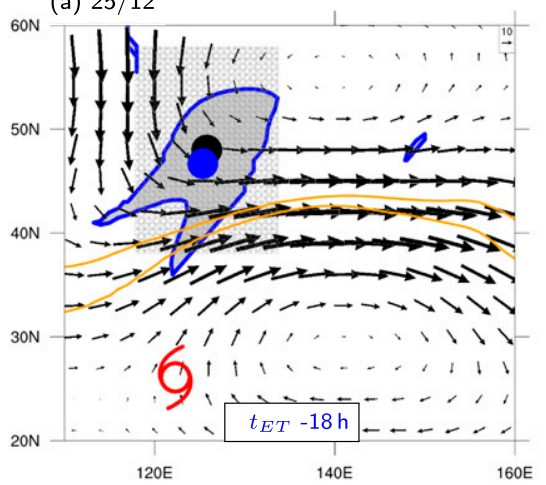

(b) $25 / 18$

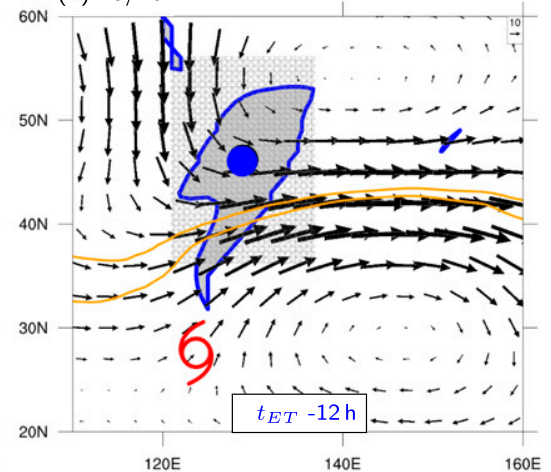

(c) $26 / 00$

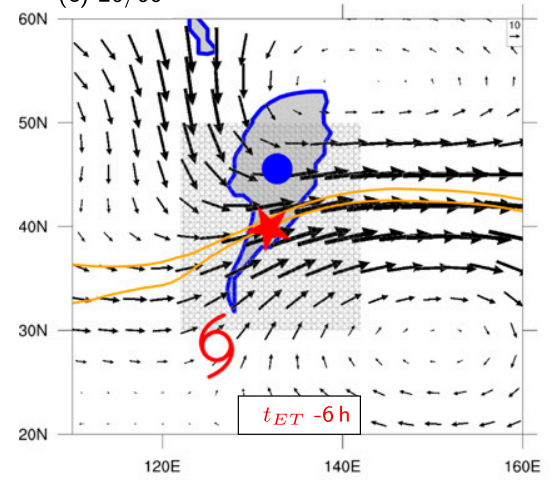

(d) $26 / 06$

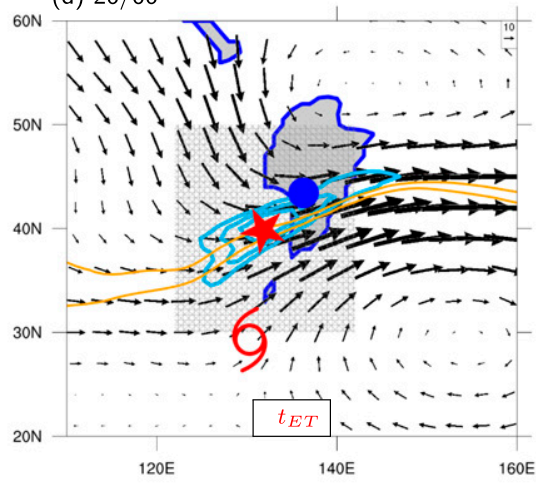

(e) $26 / 12$

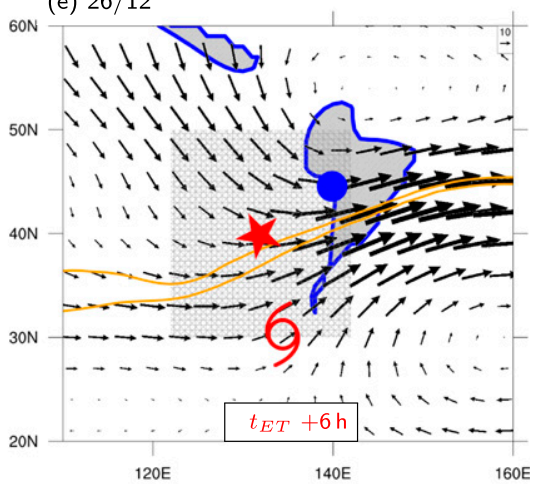

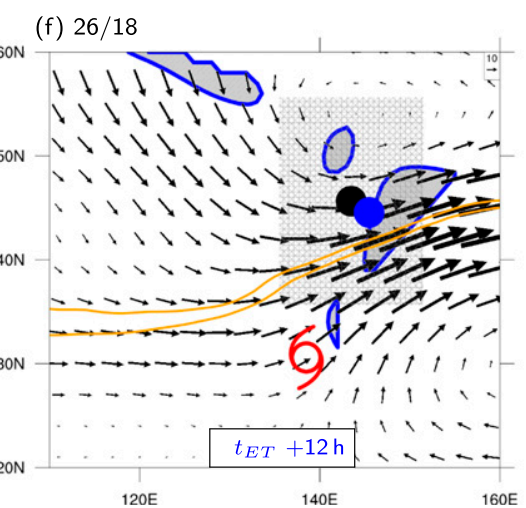

(g) $27 / 00$

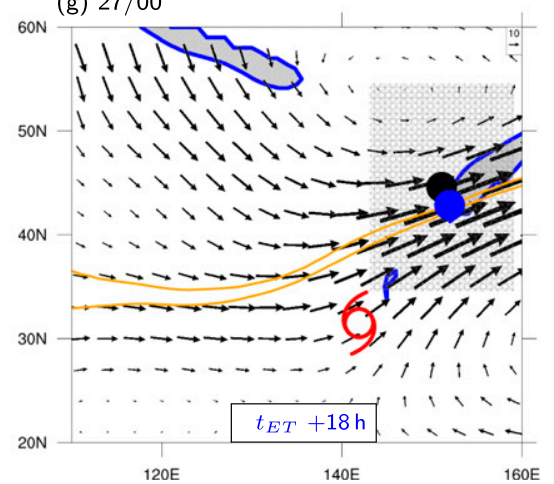

FIG. 1. Example of trough tracking for TC Nock-ten, between 1200 UTC 25 Oct and 0000 UTC 27 Oct 2004, every $6 \mathrm{~h}$ (format dd/hh). Arrows depict nondivergent wind after TC removal, and trough objects are highlighted (blue contour, dark gray shading). The light gray box depicts the region of CVA averaging at each time step and therefore contains the position of the trough center of mass (blue filled dot). Box is centered (a),(b),(f),(g) at the expected position of the trough center of mass (black dot) and (c)-(e) at the location of maximum interaction (red star). The two orange contours depict isentropically averaged (315-355 K) PV (only 2 and 3 PVU), while light blue lines in (d) indicate the $-5,-10$, and -15 PVU day ${ }^{-1}$ contours of PV advection by the irrotational component of the wind at $350 \mathrm{~K}$ at $t_{\mathrm{ET}}$.

window centered on each $t_{\mathrm{ET}}$ and in a random year between 1979 and 2013. The 95th percentile of this null distribution is used to mark statistical significance.

\section{d. Atmospheric blocking diagnostics}

A block is identified as a long-lived, slow-moving, negative PV anomaly in the upper troposphere that corresponds to a vast, coherent area of anticyclonic flow through the troposphere. To diagnose it, vertically averaged (500-150 hPa) PV anomalies with respect to the climatological PV distribution of each month are computed in ERA-Interim. These anomalies are then smoothed employing a 2-day running mean. A blocked region is then identified as a closed region of negative PV anomaly lower than $-1.3 \mathrm{PV}$ units (PVU; $1 \mathrm{PVU}=10^{-6} \mathrm{~K} \mathrm{~m}^{2} \mathrm{~kg}^{-1} \mathrm{~s}^{-1}$ ), which fulfills the following 
overlap criterion: the minimal spatial overlap of the closed regions between two subsequent 6-hourly time steps must be $70 \%$ for at least 5 consecutive days [see Schwierz et al. (2004) for further details].

Time-lagged composites of blocking frequency

$$
f_{B}\left(t^{*}\right)=\frac{\sum_{i=1}^{N_{\mathrm{TC}}} B_{i}\left(t^{*}, x, y\right)}{N_{\mathrm{ALL}}},
$$

where $B\left(t^{*}, x, y\right)$ is a two-dimensional Boolean (0-1) field highlighting blocked grid points at a time lag of $t^{*} \mathrm{~h}$ with respect to $t_{\mathrm{ET}}$. It is possible to compare this value with the climatological frequency of blocking during ASO $f_{B}^{\mathrm{ASO}}=\sum_{\mathrm{ASO}} B(t) / N_{\mathrm{ASO}}$, where $N_{\mathrm{AsO}}$ is the total number of 6-hourly time steps during all ASO months between 1979 and 2013.

The lagged blocking frequency deviations with respect to $f_{B}^{\mathrm{ASO}}$ are defined as

$$
\Delta f_{B}\left(t^{*}\right)=f_{B}\left(t^{*}\right)-f_{B}^{\mathrm{ASO}} .
$$

If $\Delta f_{B}\left(t^{*}\right)>0$, then the probability of blocking following a TC-trough interaction is increased with respect to the climatological frequency, and vice versa for $\Delta f_{B}\left(t^{*}\right)<0$.

The statistical significance of $\Delta f_{B}$ is also assessed using a bootstrapping approach. A random blocking frequency composite is computed for each TC-trough interaction, based on blocking fields $B$ from randomly chosen days in a 15-day time window centered at the calendar day of $t_{\mathrm{ET}}$ and for a randomly chosen year between 1979 and 2013. Then, $f_{B}^{\text {ASO }}$ is subtracted to obtain a random deviation $\Delta f_{B}$ from the climatology. This procedure is repeated 2500 times to obtain a distribution of random blocking frequency anomalies at each grid point. As for RWP anomalies, the 95th percentile from the distribution of random $\Delta f_{B}$ values is used to mark statistical significance.

\section{Results}

\section{a. Revisiting the downstream impact of ET}

The interaction of recurving TCs with upper-level troughs during ASO is associated with a significant increase in the amplitude of RWPs over the North Pacific in the 5 days following $t_{\mathrm{ET}}$ (Fig. 2). The outlined evolution is consistent with previous studies, which employed aggregated metrics to evaluate the effect of recurving TCs on the downstream flow (e.g., Archambault et al. 2013; Quinting and Jones 2016). Significant RWP anomalies are visible 1 day before $t_{\mathrm{ET}}$ in the western

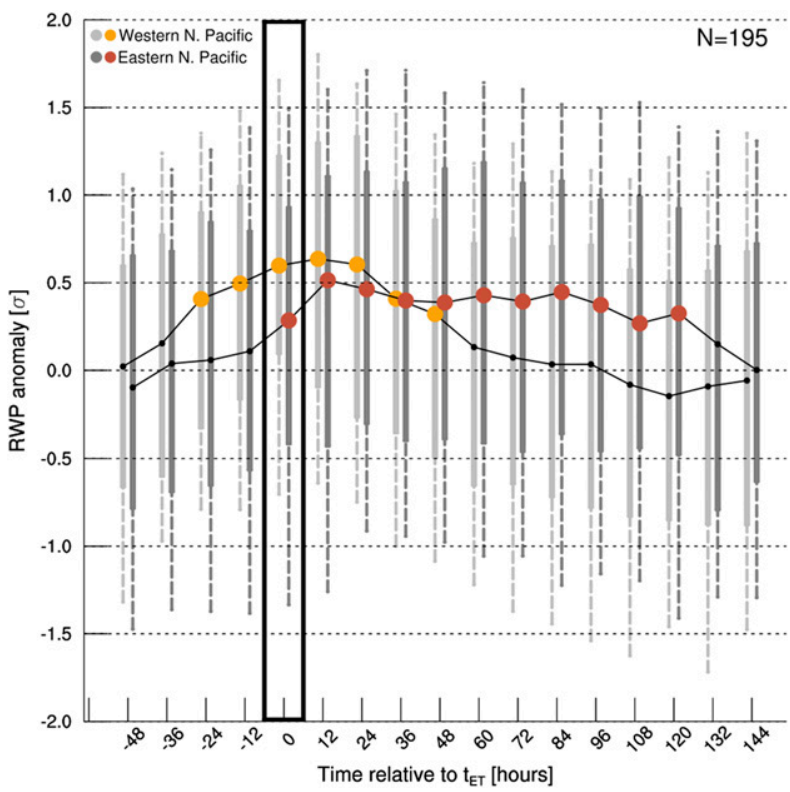

FIG. 2. Distribution of standardized anomalies with respect to $t_{\mathrm{ET}}$ of RWP amplitude for the 195 TC-trough interactions in ALL, in two areas representing the western North Pacific (light gray; $25^{\circ}-75^{\circ} \mathrm{N}, 100^{\circ} \mathrm{E}-$ $170^{\circ} \mathrm{W}$ ) and the eastern North Pacific (dark gray; $25^{\circ}-75^{\circ} \mathrm{N}, 170^{\circ} \mathrm{E}-$ $100^{\circ} \mathrm{W}$ ). The lower (upper) whisker marks the lower (upper) decile of each distribution. The filled dot in the box marks the median value, and the lower (upper) bound of the box shows the lower (upper) quartile. Filled colored dots refer to anomalies that are significantly different from climatology at the $99 \%$ confidence level. Orange dots refer to the western North Pacific, and red dots refer to the eastern North Pacific.

North Pacific and at $t_{\mathrm{ET}}$ in the eastern North Pacific (see the yellow and red points, respectively, in Fig. 2). This early emergence of significant flow amplification can be explained by the fact that as $t_{\mathrm{ET}}$ approaches and PV advection by the irrotational wind reaches its minimum, the TC is already moving northward ahead of an upstream trough (Archambault et al. 2013, their Fig. 19) and has displaced the jet poleward, causing an increase of RWP amplitude over the basin as the RWP propagates downstream.

Highly amplified RWPs often precede the onset of atmospheric blocking (Masato et al. 2012; Grams and Archambault 2016). Given this, and in light of previous studies suggesting a connection between western North Pacific ET and blocking (Small et al. 2014; Archambault et al. 2014), we explore whether statistical links exist between the TC-trough interactions belonging to ALL and the frequency of downstream blocking. Climatologically, blocking occurs $5 \%-10 \%$ of the time during ASO at the end of the Pacific storm track, south of Alaska and over the Bering Sea (black dashed lines in Fig. 3). However, the probability of atmospheric blocking at the eastern edge of the Pacific storm track is 2 times higher than climatology when TC recurvature has occurred over the western North Pacific during the previous 1-5 days 

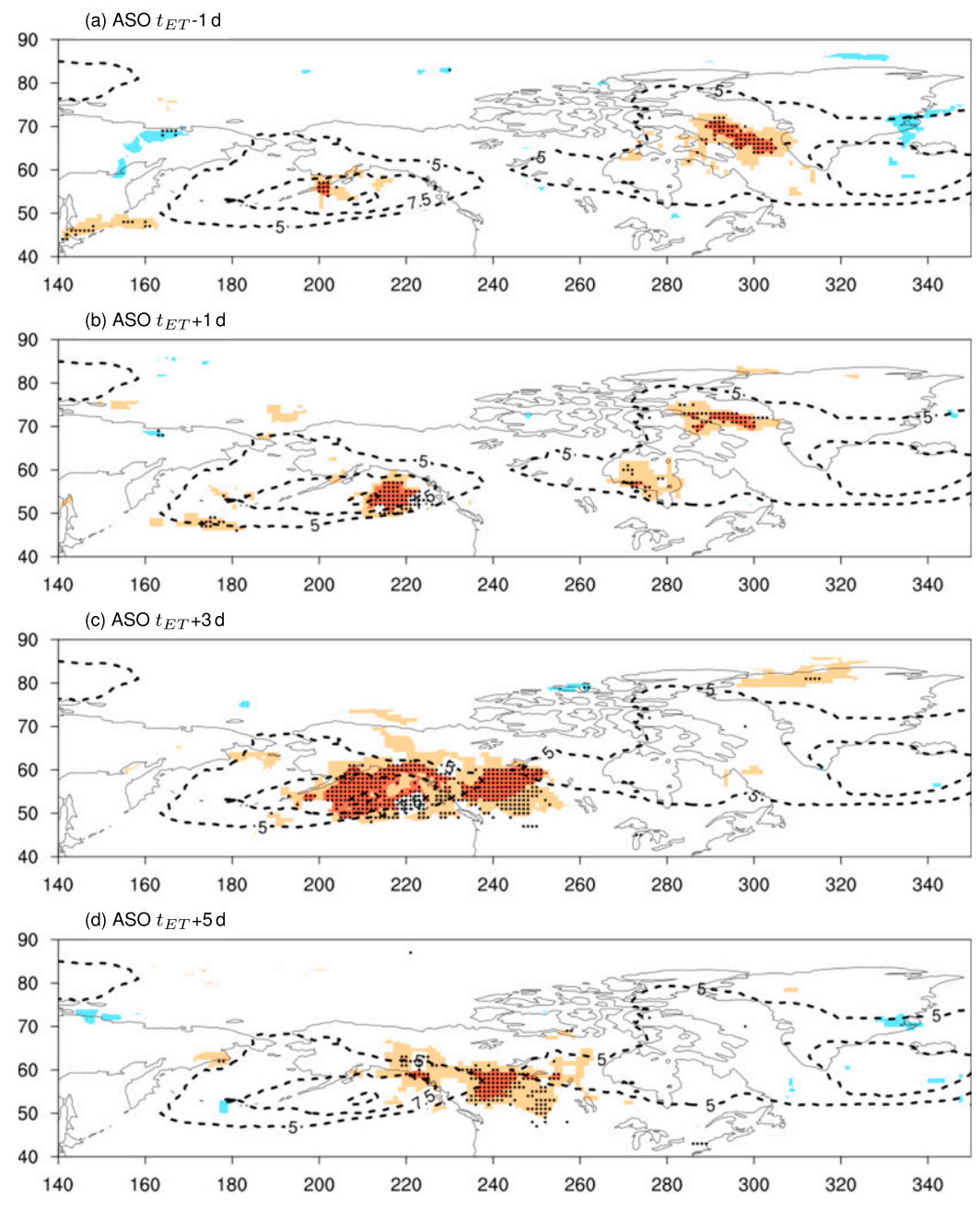

(e) ASO $t_{E T+7 d}$
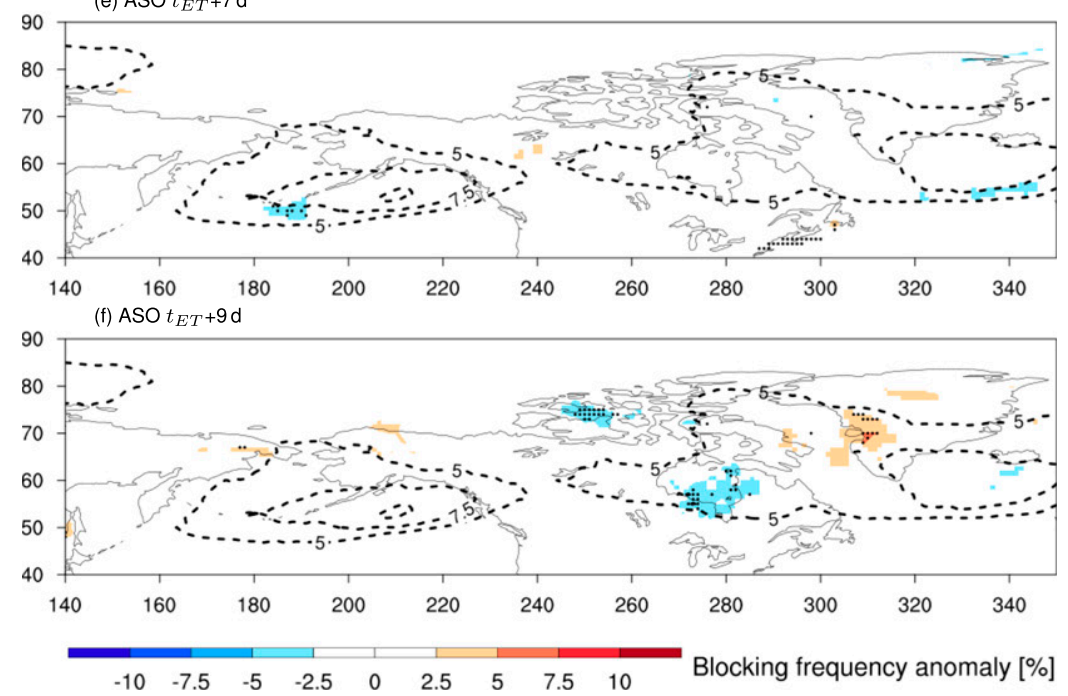

FIG. 3. Lagged composites of statistically significant values of $\Delta f_{B}$, relative to $t_{\mathrm{ET}}$, for the considered $N=195$ recurving TCs in ALL (shaded; 95\% confidence level). Stippling indicates values of $\Delta f_{B}$ that are significantly different from zero at the $99 \%$ confidence level. The 5\%, 7.5\%, and 10\% climatological blocking frequencies during ASO are marked by black dashed contours. 
(Figs. 3b-d). Blocking is mostly enhanced over the Gulf of Alaska and western Canada (i.e., in the vicinity and to the east of areas of already high climatological $f_{B}^{\mathrm{ASO}}$ ): this is consistent with the observation of enhanced RWP activity over the North Pacific following TC recurvature.

The employed diagnostics confirm previous results about the impact of transitioning TCs on RWPs and highlight the presence of atmospheric blocking downstream of ET. In the following, both these features will be investigated in detail from a phase locking perspective.

\section{b. Stratification of downstream impact}

A stratification of the 195 TC-trough interactions in ALL with respect to the variation in the zonal speed of the trough CM is performed. Trough deceleration is evaluated as the difference in trough speed right after and before $t_{\mathrm{ET}}$, using a "slowdown metric" $S=c\left(t_{\mathrm{ET}}+12 \mathrm{~h}\right)-c\left(t_{\mathrm{ET}}-48 \mathrm{~h}\right)$. The distribution of $S$ highlights that most of the upperlevel troughs decelerate during the interaction with the TC (Fig. 4a). Approximately $1 / 4$ of the considered troughs, however, do not decelerate during TC-trough interaction or even slightly accelerate (Fig. 4a). We consider the upper and the lower quartiles of the $S$ distribution to define a subset of, respectively, strongly decelerating (DECEL) and accelerating (ACCEL) upper-level troughs during TC-trough interaction (TCs belonging to the two subsets are listed in Tables S1 and S2). The evolution of $c$ differs substantially between the two subsets (Fig. 4b): while ACCEL troughs steadily accelerate during TC-trough interaction, DECEL troughs rapidly decrease their speed between $t_{\mathrm{ET}}-48 \mathrm{~h}$ and $t_{\mathrm{ET}}+18 \mathrm{~h}$ and almost stagnate around $t_{\mathrm{ET}}$ (cf. the orange and the indigo lines of Fig. 4b).

As discussed in the introduction, previous work has shown that the variability in downstream impact is mostly related to the phasing of the transitioning TC with an upstream trough. Indeed, the presence of trough deceleration appears to modulate the amplitude of downstream RWPs (Fig. 5). DECEL cases feature stronger RWP amplitude anomalies after $t_{\mathrm{ET}}$ than in the ALL subset, both in the western and eastern North Pacific (cf. the evolution of the indigo and blue dots in Fig. 5a with the yellow and red dots of Fig. 2). On the other hand, according to this metric, no significantly amplified RWPs are observed for ACCEL cases in the 5 days following $t_{\mathrm{ET}}$ (orange and dark red dots in Fig. 5b). Therefore, the impact of TCs in ACCEL is virtually indistinguishable from the ASO climatology of RWP activity over the North Pacific waveguide. The significantly positive anomalies in the western North Pacific observed $36 \mathrm{~h}$ before and $120 \mathrm{~h}$ after $t_{\mathrm{ET}}$ in ACCEL are not reflected in Fig. 2 and do not appear to be related to the analyzed
TC-trough interactions. Given that the source of such anomalies is probably unrelated to the phasing between the TC and the trough, no attempt to understand them is undertaken here.

\section{c. Composite analysis}

Composites centered at the location of minimum PV advection by the irrotational wind at $t_{\mathrm{ET}}$ are employed to better characterize the flow evolution in the vicinity and downstream of the transitioning TC. Standardized differences (i.e., in units of standard deviations $\sigma_{\mathrm{ALL}}$ ) of vertically averaged upper-level $\mathrm{PV}$ anomaly (in the layer $315-355 \mathrm{~K}$ ) are used to highlight the differences between the two subsets (Torn et al. 2015; Riboldi et al. 2018). Such differences are defined at each grid point as

$$
\Delta \mathrm{PVA}=\frac{\mathrm{PVA}_{\mathrm{DECEL}}-\mathrm{PVA}_{\mathrm{ACCEL}}}{\sigma_{\mathrm{ALL}}},
$$

and their statistical significance is assessed by bootstrapping 2500 times the $\triangle$ PVA fields obtained from two randomly selected subsets of 49 cases in ALL.

Before TC-trough interaction, the TC moves northeastward and approaches an upper-level trough embedded in the jet stream, represented by the positive PV anomaly $10^{\circ}-20^{\circ}$ upstream (Figs. 6a,b,d,e). No significant differences between the two subsets are visible before $t_{\mathrm{ET}}$ (Figs. 6c,f), except for the meridional extension of the upstream trough, reaching farther south in DECEL than in ACCEL and highlighted by a region of significantly positive $\triangle \mathrm{PVA}$ located $10^{\circ}$ west of the location of maximum interaction at $t_{\mathrm{ET}}-24 \mathrm{~h}$ (Fig. 6f). The evolution of the two composites begins to differ at $t_{\mathrm{ET}}$ (Figs. $6 \mathrm{~g}-\mathrm{i}$ ). The meridional elongation and the slightly negative [westward or southeast (SE)northwest (NW)] tilt of the upstream trough in DECEL corresponds to the formation of a jet streak and to the northward extension of a ridge downstream of the TC (i.e., the negative PV anomaly). A trough forms downstream of that ridge, highlighted by a second jet streak (Fig. 6g): this is an indication of downstream development. The TC in the DECEL composite undergoes jet crossing between 1 and 2 days after $t_{\mathrm{ET}}$ and eventually is located (in a composite sense) near the left exit of the jet stream: this could indicate extratropical reintensification of the storm (Figs. 6g,j,m; see also section 3d). On the other hand, ACCEL interactions feature a positively tilted [eastward or southwest (SW)northeast (NE)] trough in the vicinity of the interaction point at $t_{\mathrm{ET}}$, associated with a less meridionally extended ridge (Fig. 6h). A negative PV anomaly stronger than 2 PVU is present also for this subset, but it is strong only at $t_{\mathrm{ET}}$, and no downstream development is evident (Fig. 6h). The evolution of downstream RWPs is very different in the two subsets (Figs. 6j-r). Downstream development 
(a) S distribution

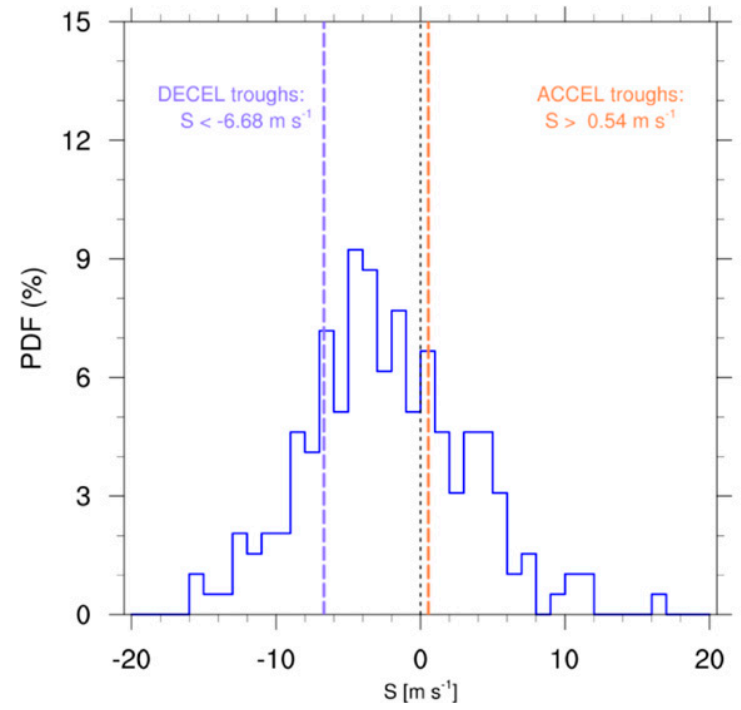

(b) Trough speed

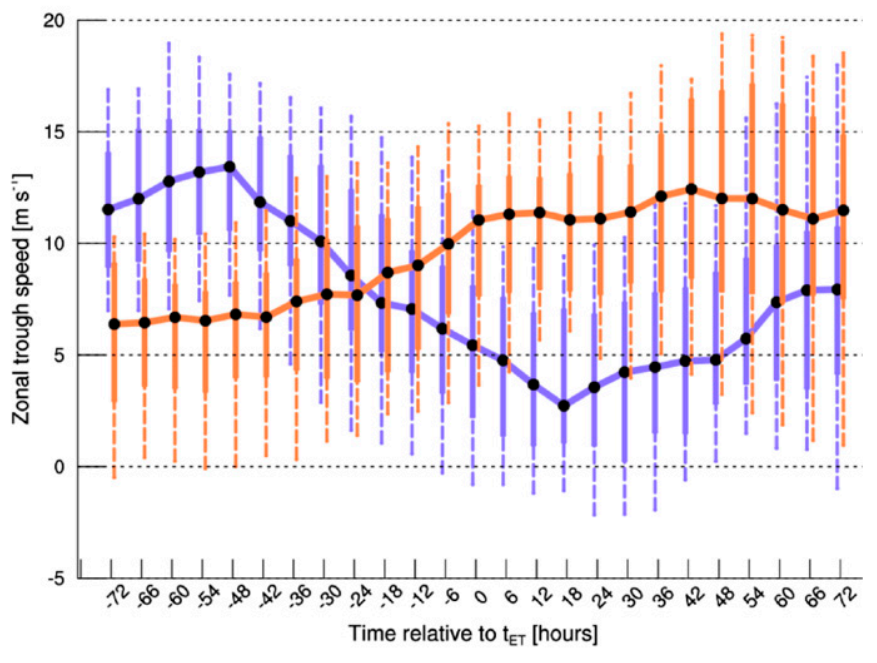

FIG. 4. (a) Distribution of slowdown metric $S$ for the considered set of 195 TC-trough interactions. The dashed indigo and orange lines indicate the locations of the lower and upper quartiles of the distribution, respectively. (b) Time series of zonal trough speed (in $\mathrm{m} \mathrm{s}^{-1}$ ) distributions for the DECEL (indigo) and ACCEL (orange) subsets, relative to $t_{\mathrm{ET}}$. Box-and-whisker diagrams as in Fig. 2.

continues as DECEL cases are associated with a sequence of positive and negative PV anomalies along the waveguide, which are related to amplified troughs and ridges (Figs. 6j,m,p). On the other hand, the ridge visible around $t_{\mathrm{ET}}$ downstream of the TC in ACCEL weakens while being advected eastward during the following days, as the jet core does not get displaced meridionally (Figs. 6k,n,q).

(a) DECEL

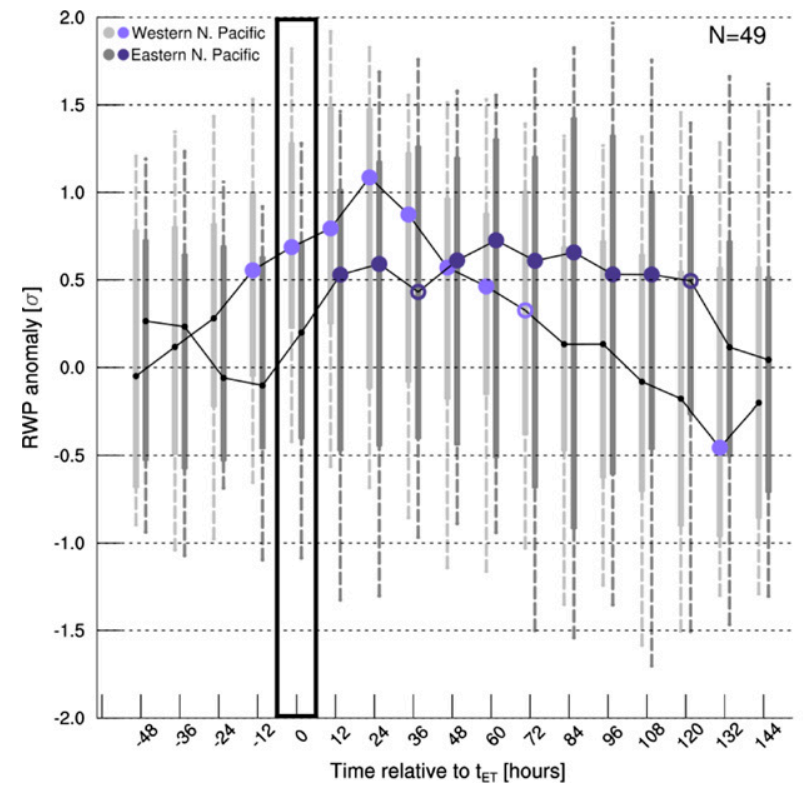

A Hovmoeller diagram of upper-level meridional wind provides a compact depiction of phasing and RWP amplification in each subset (Fig. 7). In DECEL, the mean TC track remains ahead of the trough CM (without overtaking it) in the 3.5 days between $t_{\mathrm{ET}}-24 \mathrm{~h}$ and $t_{\mathrm{ET}}+60 \mathrm{~h}$ (Fig. 7a), while this is the case only between $t_{\mathrm{ET}}-12 \mathrm{~h}$ and $t_{\mathrm{ET}}+12 \mathrm{~h}$ for ACCEL cases. In DECEL,

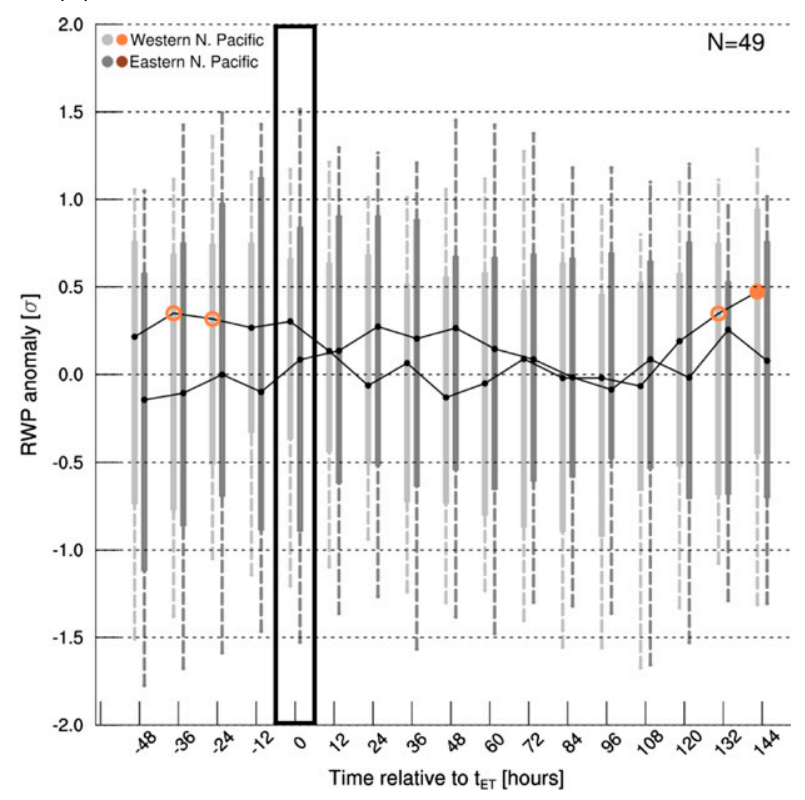

FIG. 5. As in Fig. 2, but for $N=49$ TCs in the (a) DECEL and (b) ACCEL subsets. Empty dots refer to anomalies that are significantly different from climatology at the $95 \%$ confidence level, while filled dots highlight significance at the $99 \%$ confidence level. 
(a) DECEL $t_{E T}-2 \mathrm{~d}$

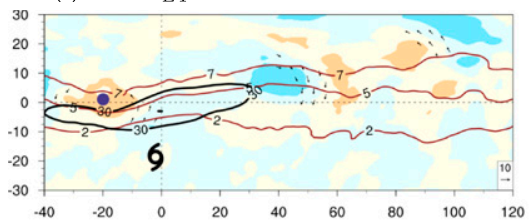

(d) DECEL $t_{E T}-1 \mathrm{~d}$

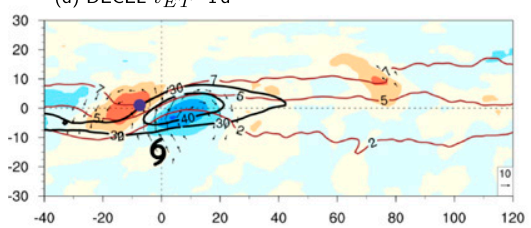

(g) DECEL $t_{E T}$

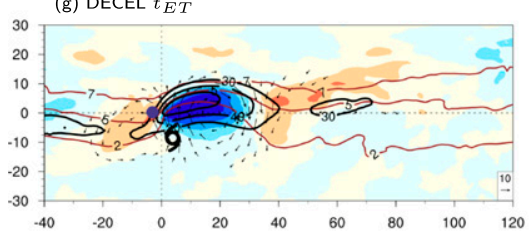

(j) DECEL $t_{E T}+1 \mathrm{~d}$

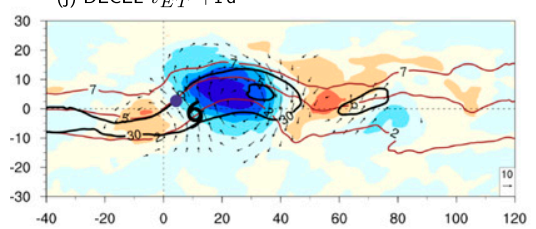

(m) DECEL $t_{E T}+2 \mathrm{~d}$

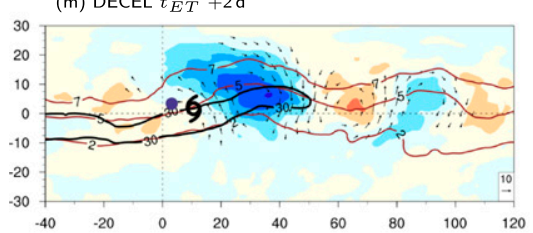

(p) DECEL $t_{E T}+3 \mathrm{~d}$

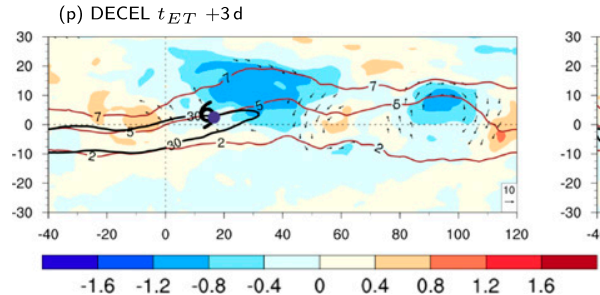

(b) ACCEL $t_{E T}-2 \mathrm{~d}$

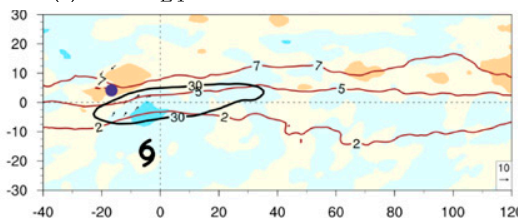

(e) ACCEL $t_{E T}-1 \mathrm{~d}$

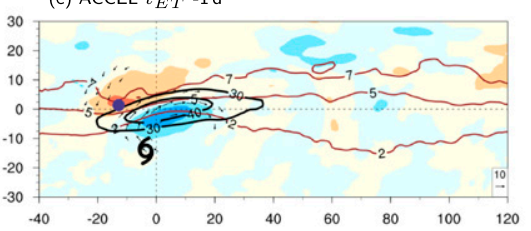

(h) ACCEL $t_{E T}$

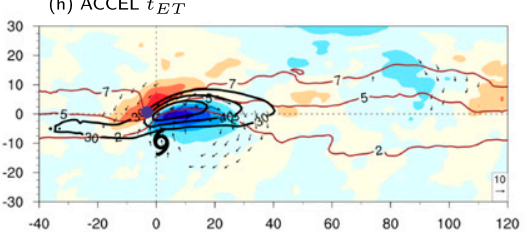

(k) ACCEL $t_{E T}+1 d$

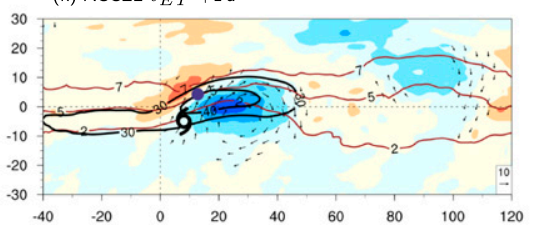

(n) ACCEL $t_{E T}+2 \mathrm{~d}$

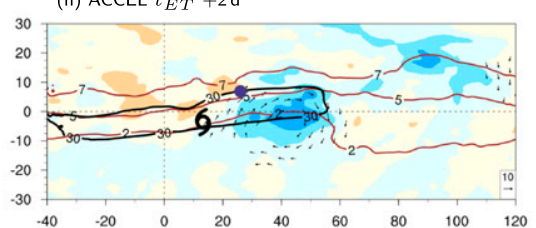

(q) ACCEL $t_{E T}+3 \mathrm{~d}$

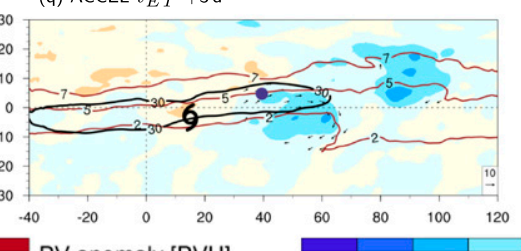

(c) Diff. DECEL - ACCEL $t_{E T}-2 \mathrm{~d}$

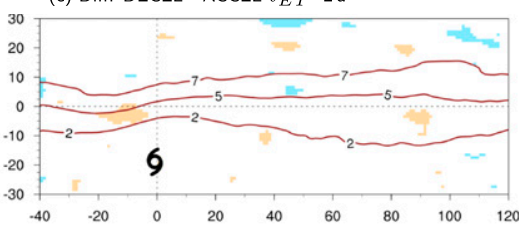

(f) Diff. DECEL - ACCEL $t_{E T}-1 \mathrm{~d}$

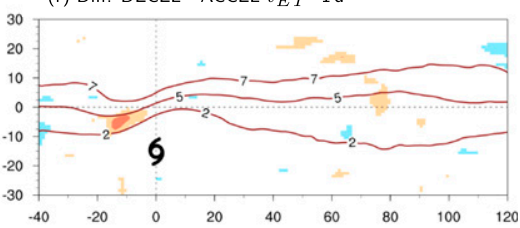

(i) Diff. DECEL - ACCEL $t_{E T}$

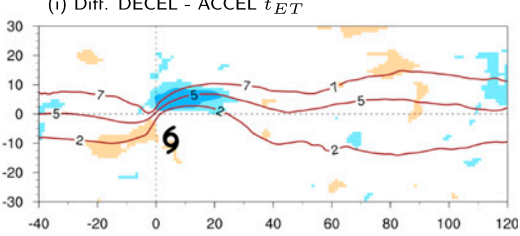

(I) Diff. DECEL - ACCEL $t_{E T}+1 d$

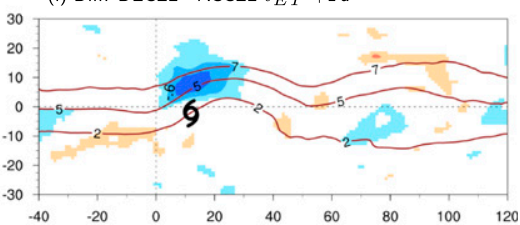

(o) Diff. DECEL - ACCEL $t_{E T}+2 \mathrm{~d}$

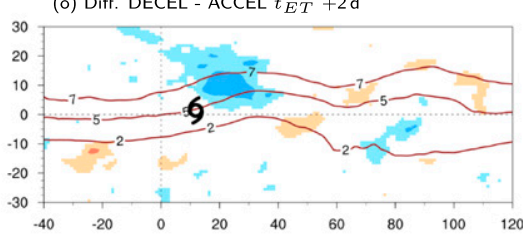

(r) Diff. DECEL - ACCEL $t_{E T}+3 \mathrm{~d}$

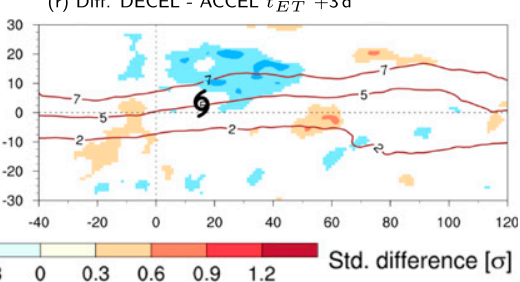

FIG. 6. Lagged composites for the (left) DECEL and (middle) ACCEL subsets at times $-2,-1, \ldots,+2,+3$ days with respect to $t_{\mathrm{ET}}$, centered at the location of maximum interaction, of vertically averaged PV anomaly (shaded) and wind anomaly (wind vectors; plotted only if larger than $5 \mathrm{~m} \mathrm{~s}^{-1}$ ) in the 315-355-K isentropic layer, superimposed by the composite PV (brown contours; only for 2, 5, and 7 PVU) and wind speed (black contours) on the $345-\mathrm{K}$ isentropic layer. Median position of TCs is marked by the black TC symbol, while that of the trough CMs is marked by the blue filled dot. (right) Significant (at $95 \%$ confidence level) standardized differences between the DECEL and ACCEL subsets (shaded) and composite PV at $345 \mathrm{~K}$ (only 2, 5, and 7 PVU) for the $N=195$ TC-trough interactions in ALL.

the RWP amplifies and propagates downstream, while in ACCEL, a weaker RWP emerges and dissipates while propagating rapidly downstream (see the green dashed line indicating group speed in Fig. 7).

The mean tracks of TCs involved in DECEL and ACCEL interactions are clearly differentiated from each other when observed from the perspective of the trough (Fig. 8). Even if all the considered TCs recurve with respect to the position of maximum interaction (Fig. 8a), most ACCEL TCs do not recurve in a frame of reference that is moving with the trough $\mathrm{CM}$ and head westward after $t_{\mathrm{ET}}$ (orange bold line in Fig. 8b). On the 
(a) DECEL

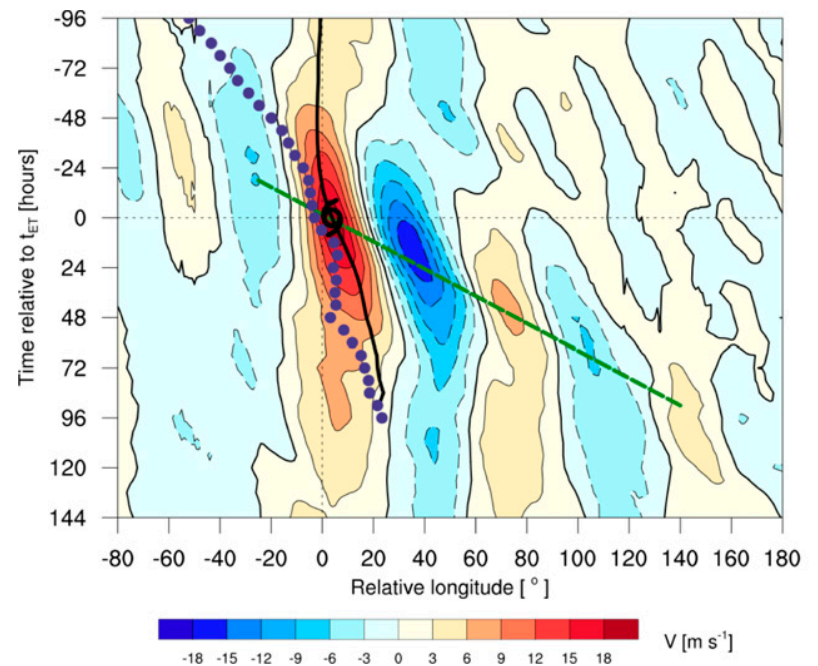

(b) ACCEL

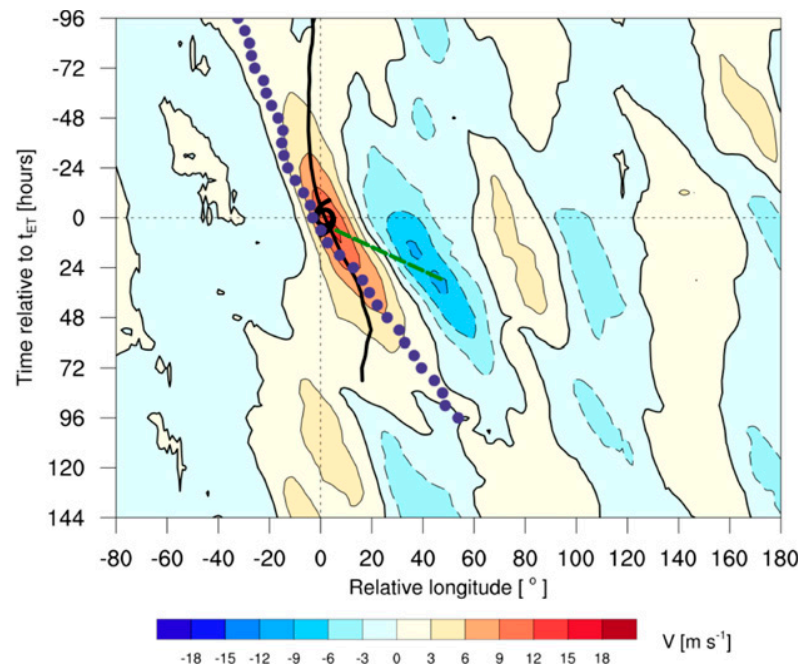

FIG. 7. Hovmoeller diagram of 345-K meridional wind for the $N=49$ TCs in the (a) DECEL and (b) ACCEL subsets, averaged for each interaction in a $30^{\circ}$ latitudinal band centered at the location of maximum interaction at $t_{\mathrm{ET}}$ (shaded; every $3 \mathrm{~m} \mathrm{~s}^{-1}$; negative values dashed). The black line indicates the average TC track, while the blue dots indicate the median longitude of the diagnosed trough CM at each time step. The green dashed lines depict the propagation of the center of the upper-level wave packet and were drawn by hand following the locations of maxima and minima of the meridional wind.

other hand, most DECEL cases recurve in a troughrelative frame of reference and therefore remain ahead of the upstream trough for a longer time (bold indigo line in Fig. 8b). Track bifurcation in the two subsets is indicative of differences in the structure of the largescale flow, which will be discussed in the next section.

\section{d. Contribution of the large-scale flow}

Differences in forcing for ascent and phase locking highlight that DECEL troughs feature an environment more conducive to downstream cyclogenesis than ACCEL troughs: these favorable conditions of the large-scale flow act to magnify the downstream impact of DECEL TCtrough interactions.

As already performed in the context of ET by Riemer and Jones (2010), Grams et al. (2013a), and Riemer et al. (2014), forcing for ascent is evaluated for the DECEL and ACCEL subsets by inverting the divergence of the $\mathbf{Q}$ vector on pressure layers between 900 and $100 \mathrm{hPa}$ to obtain the vertical velocity $\omega$ [Fig. 9; see Davies (2015) for a review]. A partitioning of $\mathbf{Q}$ into its shearwise $\left(Q_{s}\right)$ and transverse $\left(Q_{n}\right)$ components with respect to the local horizontal potential temperature gradient is additionally performed (see Fig. S2). The quasigeostrophic (a) ET-relative

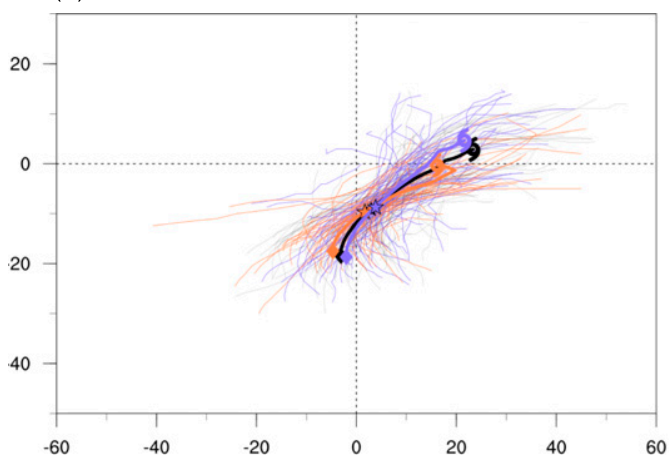

(b) CM-relative

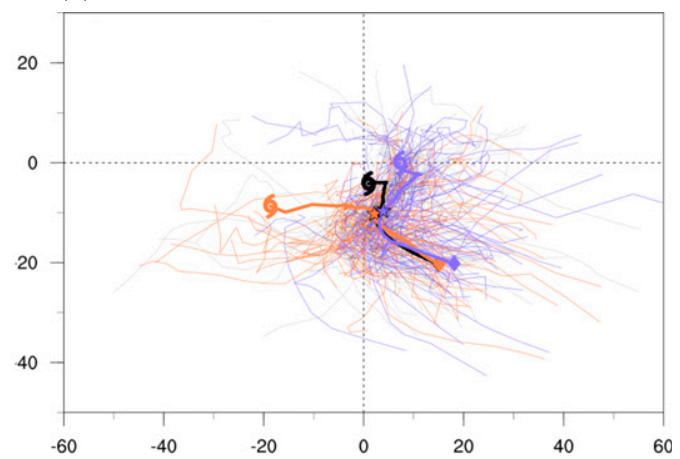

FIG. 8. Tracks of the considered 195 TCs with respect to (a) the location of maximum interaction and (b) the trough CM (both located at the origin of the relative latitude/longitude axes), with DECEL (indigo), ALL (gray), and ACCEL (orange) tracks highlighted. Mean tracks between $t_{\mathrm{ET}}-48 \mathrm{~h}$ and $t_{\mathrm{ET}}+72 \mathrm{~h}$ are highlighted by bold lines (respectively, in indigo, black, and orange). Diamonds indicate (a) ET-relative and (b) CM-relative mean TC locations at $t_{\mathrm{ET}}-48 \mathrm{~h}$, stars at $t_{\mathrm{ET}}$, and TC symbols at $t_{\mathrm{ET}}+72 \mathrm{~h}$. 
(a) DECEL - $\omega @ 700 \mathrm{hPa}$

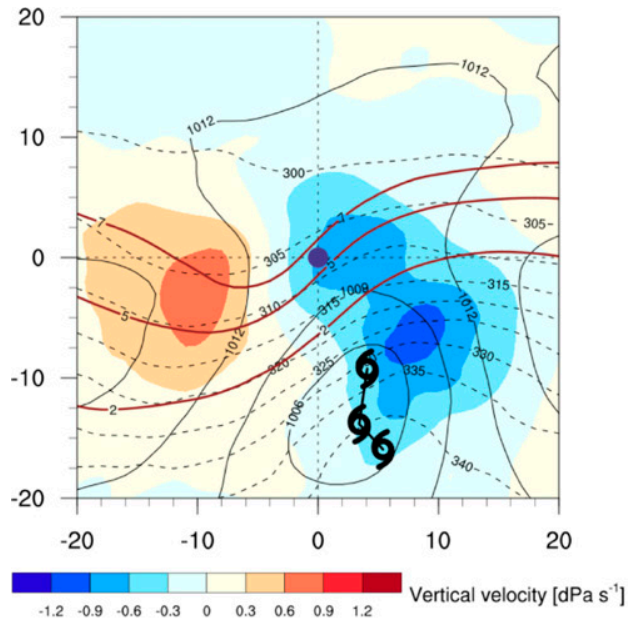

(c) DECEL - $\omega_{s} @ 700 \mathrm{hPa}$

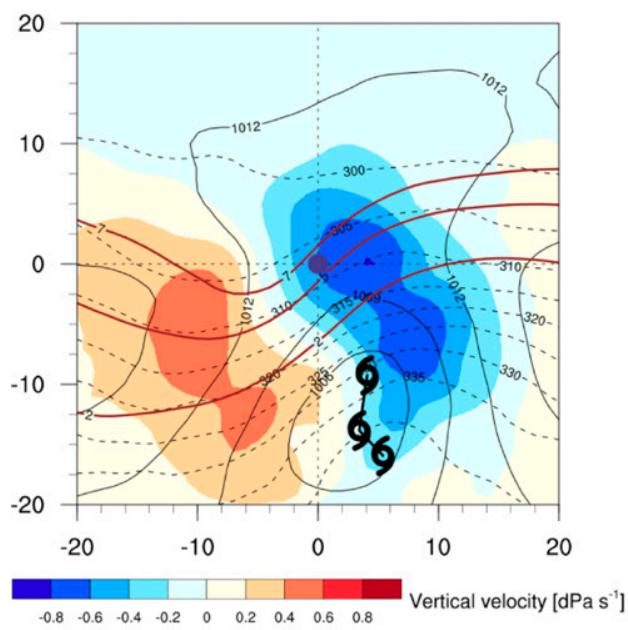

(e) DECEL - $\omega_{n} @ 700 \mathrm{hPa}$

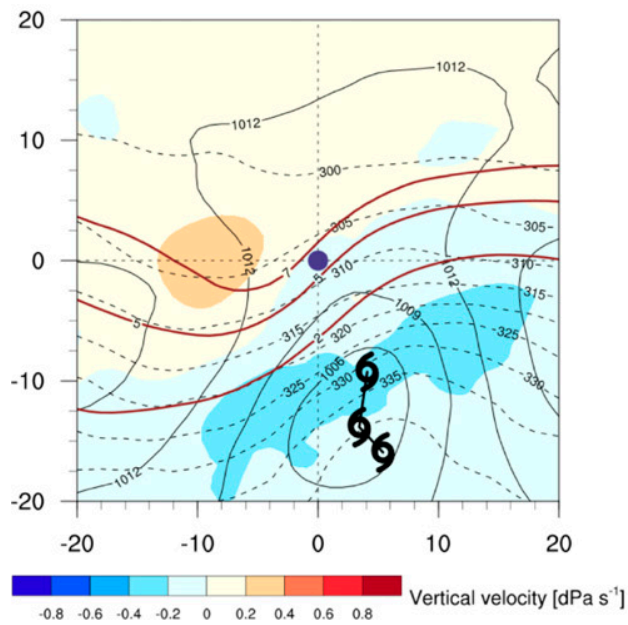

(b) ACCEL - $\omega @ 700 \mathrm{hPa}$

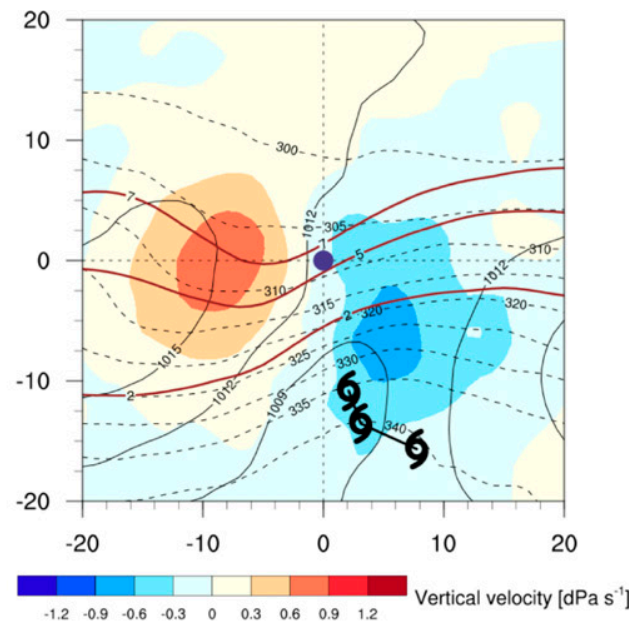

(d) ACCEL $-\omega_{s} @ 700 \mathrm{hPa}$

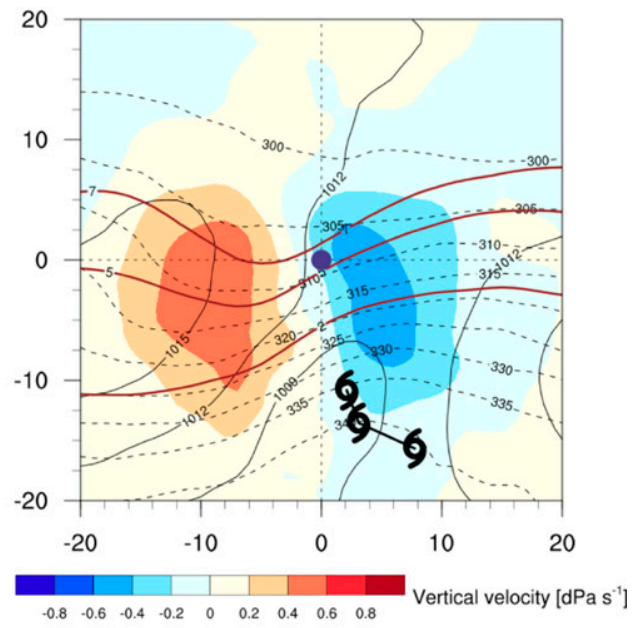

(f) ACCEL - $\omega_{n} @ 700 \mathrm{hPa}$

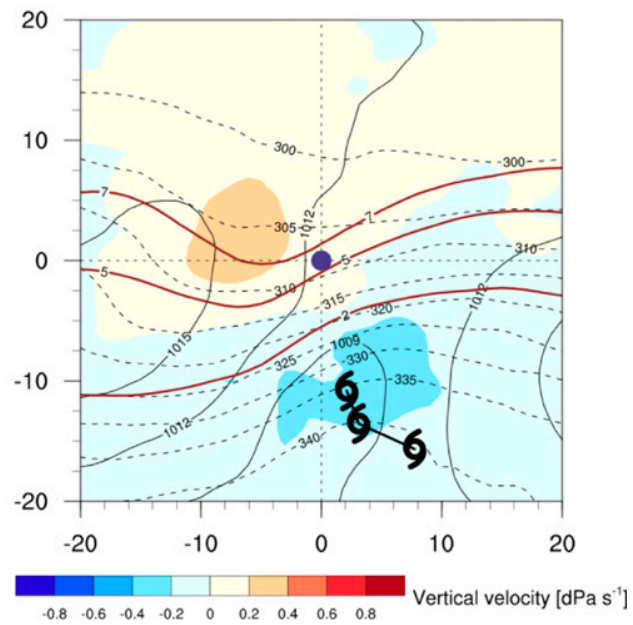

FIG. 9. (a),(b) Trough CM-centered (blue dot) composites of quasigeostrophic vertical velocity at $700 \mathrm{hPa}$, averaged between $t_{\mathrm{ET}}-24 \mathrm{~h}$ and $t_{\mathrm{ET}}$ every $12 \mathrm{~h}$. Vertical velocity is further divided in two components $\omega_{s}$ and $\omega_{n}$ forced, respectively, by the (c),(d) shearwise and (e),(f) transverse $\mathbf{Q}$-vector component with respect to the horizontal potential temperature gradient on isobaric surfaces. Composites of PV at $350 \mathrm{~K}$ (bold brown 
vertical velocity related to the divergence of $Q_{s}$ and $Q_{n}$ is then computed from the $\omega$ equation (Keyser et al. 1992; Martin 2006). As Martin (2006, 2007) pointed out, shearwise ascent $\left(\omega_{s}\right)$ is intimately related to the genesis and the deepening of surface cyclones, as it is capable of changing the direction of the potential temperature gradient; on the other hand, transverse ascent $\left(\omega_{n}\right)$ is related to frontal circulations and is responsible for changing the strength of the temperature gradient itself.

The performed analysis shows that ascending motions are overall stronger during DECEL interactions than in ACCEL (Figs. 9a,b). However, DECEL interactions feature more favorable conditions for baroclinic growth and subsequent ridge building than ACCEL because of the high values of $\omega_{s}$ downstream of the trough (Figs. 9c,d). On the other hand, $\omega_{n}$ has a similar magnitude in the two subsets and is overall weaker than $\omega_{s}$, pointing to the fact that $Q_{s}$ is most useful to describe the differences in forcing for ascent between ACCEL and DECEL (Figs. 9e,f).

The deformation of the low-level potential temperature gradient due to $\omega_{s}$ induces a thermal wave ahead of the meridionally elongated trough in DECEL, such that a positive potential temperature anomaly can be found ahead of the trough already one day before $t_{\mathrm{ET}}$ (Fig. 10a). The potential temperature anomaly occupies the western portion of the developing ridge and intensifies with time, together with the surface pressure minimum in proximity of the TC (Figs. 10c,e). Given that the positive, low-level potential temperature anomaly is located at the western side of the ridge, $1 / 4$ wavelength away from the center of the upper-level positive PV anomaly, this is a suitable phase shift for sustained baroclinic growth due to phase locking (Hoskins et al. 1985).

On the other hand, ACCEL troughs do not exhibit a strong baroclinic interaction between the trough and the low-level potential temperature anomaly (Figs. 10b,d). The upstream trough is positively tilted and is associated with a negative low-level temperature anomaly, while the positive potential temperature anomaly is weaker and remains in the vicinity of the TCs (Fig. 10f). Such an anomaly gets advected eastward in the warm sector of a broad low pressure area located directly downstream of the trough. An analogous evolution, featuring the eastward displacement of the warm, moist air mass related to the TC, was observed for TC-jet stream interactions not leading to Rossby wave initiation (Riboldi et al. 2018). The relevance of phase locking can also explain why RWP amplification during ET is more difficult in a low-waviness configuration, where only troughs with small amplitude are present (Torn and Hakim 2015; Riboldi et al. 2018).

The favorable conditions to baroclinic development can be linked to the observed evolution of TC intensity in the two subsets (Fig. 11). TCs in DECEL weaken less rapidly than TCs in ACCEL, even if they do not exhibit a clear reintensification signature. The higher intensity may be related to the jet crossing observed in the composite. Both the southward elongation of the upstream trough and the strong ridge downstream of the TC promote a northward motion of midlatitude cyclones and have been related to jet crossing and deepening of extratropical cyclones (Coronel et al. 2015). Conversely, ACCEL cases feature overall less deep TCs that remain at the equatorward side of the jet stream and weaken steadily with time. The presence of a positively tilted trough upstream of the TC has been shown not to be conducive to posttransition reintensification (Ritchie and Elsberry 2003).

\section{e. Contribution of diabatic processes}

After having examined how large-scale forcing can lead to phase locking during ET, the role of diabatic processes is now considered.

The poleward advection of warm and moist air lads to heavy precipitation and strong latent heat release that can contribute synergistically to increase the amplitude of RWPs downstream of ET (Bosart and Lackmann 1995; Grams and Archambault 2016). This happens mainly in two ways: 1) by directly inducing a negative PV anomaly at the waveguide, as low-PV air is advected poleward in the direction of the jet stream, and 2) by indirectly inducing the deceleration of the upstream upper-level trough, which helps to establish phase locking with lower-level temperature anomalies.

Recurving TCs featuring sustained negative PV advection by the irrotational wind along the eastern side of the trough were associated with strong downstream impact [strong interaction cases; see Archambault et al. $(2013,2015)]$. On the other hand, the opposite held in cases of weak PV advection by the irrotational wind

\footnotetext{
$\leftarrow$

contours), equivalent potential temperature at $850 \mathrm{hPa}$ (dashed black contours), and surface-level pressure (hPa; thin black contours) between $t_{\mathrm{ET}}-24 \mathrm{~h}$ and $t_{\mathrm{ET}}$ are overlaid for the $N=49$ TCs of the (left) DECEL and (right) ACCEL subsets. Median position of TCs at $t_{\mathrm{ET}}-24 \mathrm{~h}, t_{\mathrm{ET}}-12 \mathrm{~h}$, and $t_{\mathrm{ET}}$ for each subset are indicated by the black TC symbols.
} 
(a) DECEL- $t_{E T}-1 \mathrm{~d}$

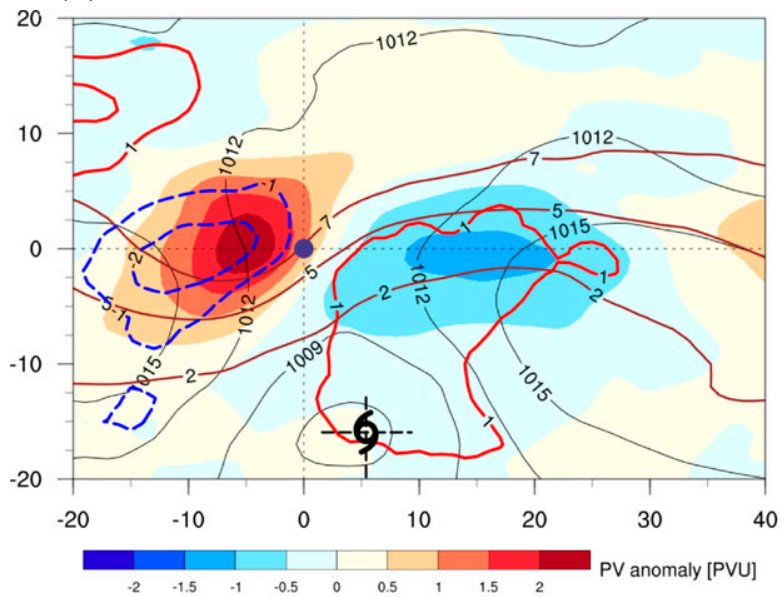

(c) DECEL $-t_{E T}$

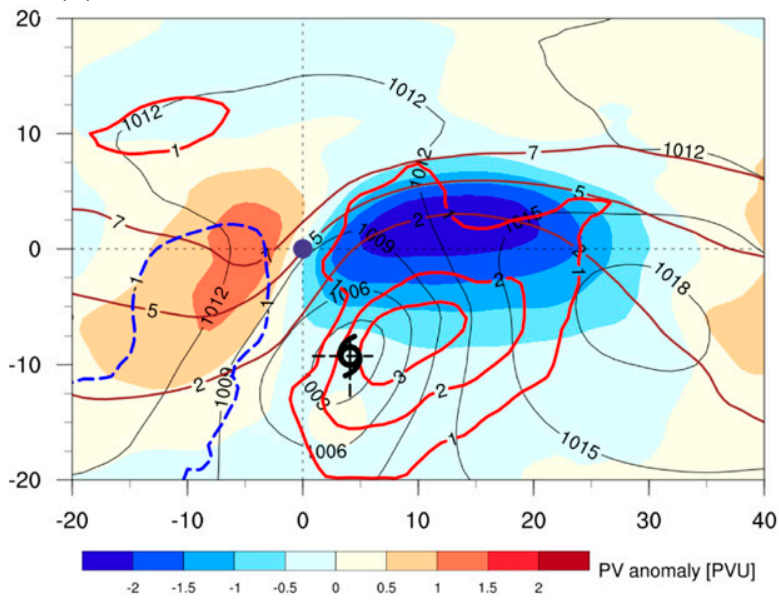

(e) DECEL $-t_{E T+1 d}$

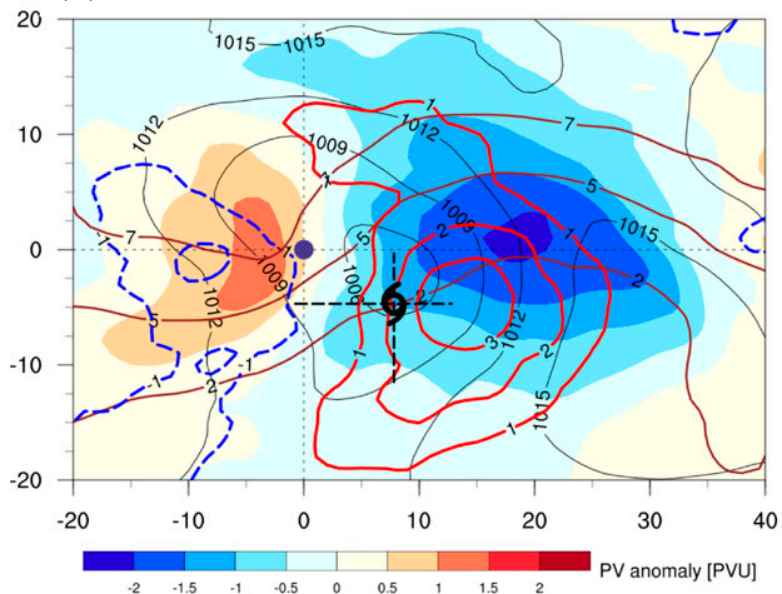

(b) ACCEL- $t_{E T}-1 \mathrm{~d}$

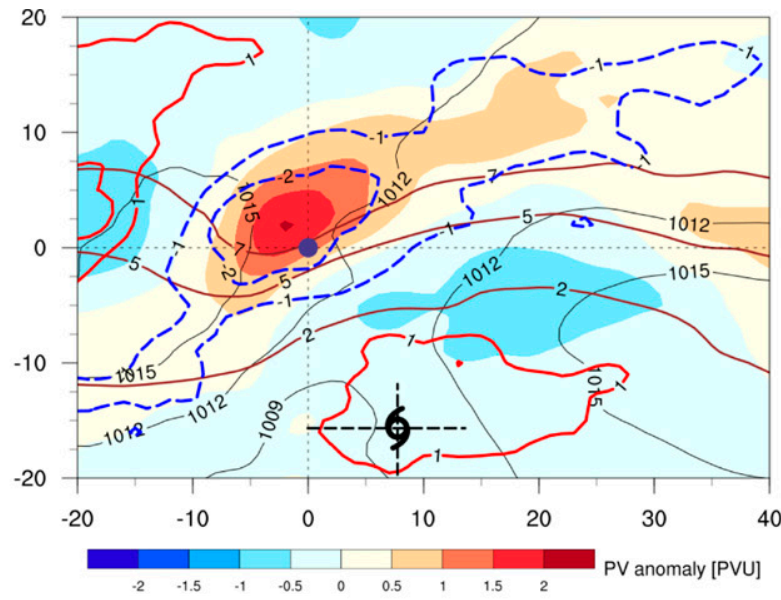

(d) ACCEL - $t_{E T}$

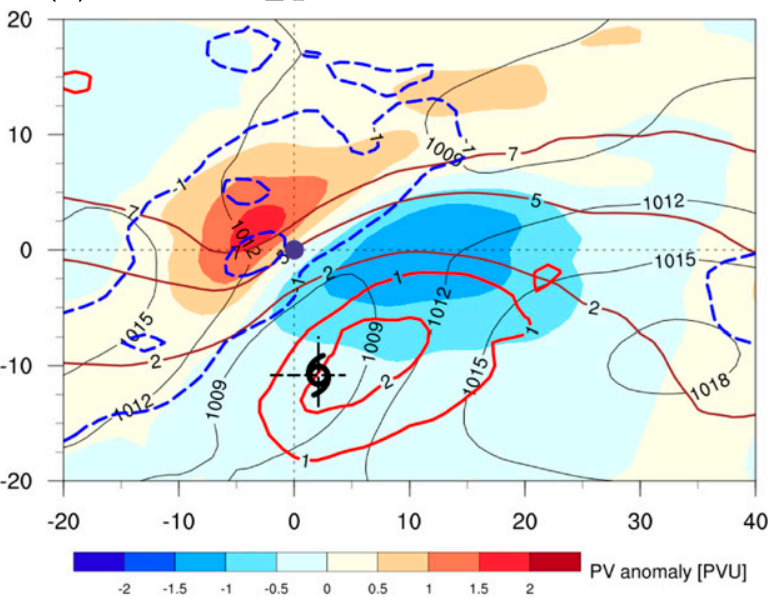

(f) ACCEL $-t_{E T}+1 \mathrm{~d}$

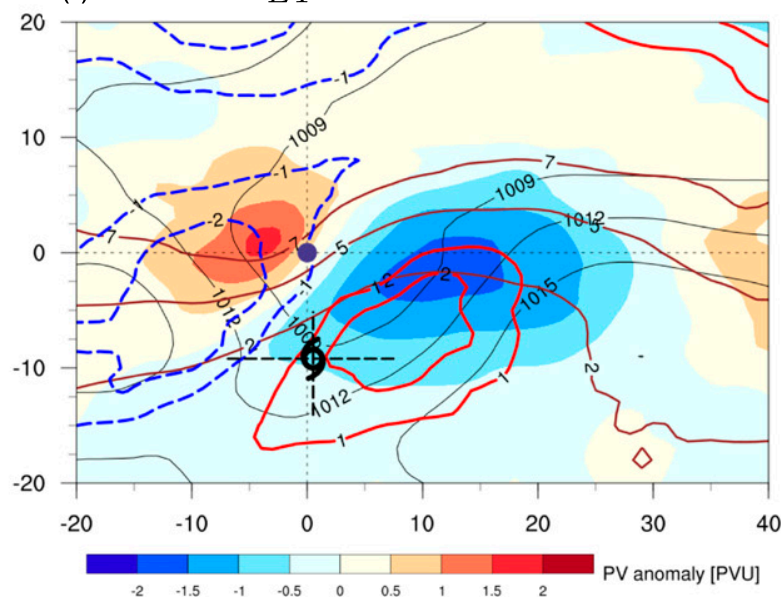

FIG. 10. Trough CM-centered (blue dot) composites of vertically averaged (315-355 K) PV anomaly (shaded), 850-hPa potential temperature anomaly (every $1 \mathrm{~K}$; positive values in red, negative in blue), $\mathrm{PV}$ at $350 \mathrm{~K}$ (bold brown contours), and surface-level pressure (hPa; thin black contours) at (a),(b) $t_{\mathrm{ET}}-24 \mathrm{~h}$, (c),(d) $t_{\mathrm{ET}}$, and (e),(f) $t_{\mathrm{ET}}+24 \mathrm{~h}$ for the $N=49 \mathrm{TCs}$ of the (left) DECEL and (right) ACCEL subsets. Median position of TCs indicated by the black TC symbol, the interquartile range of TC positions by the bold dashed lines. 


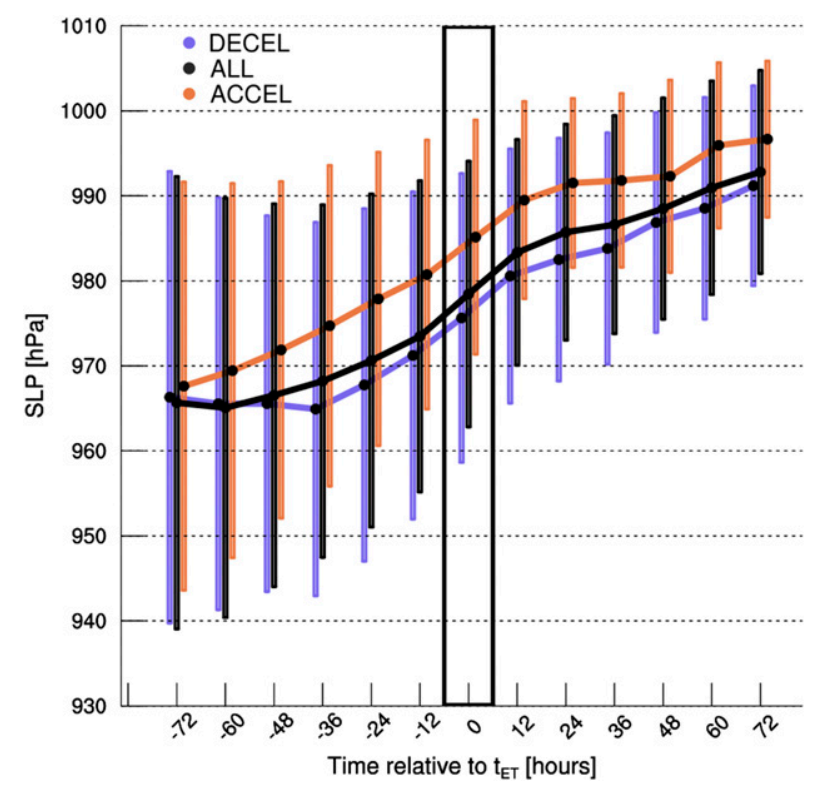

FIG. 11. Time series of mean (filled dots; connected by bold lines) and standard deviation (vertical bars) of central SLP, relative to $t_{\mathrm{ET}}$, for TCs in ALL (black), DECEL (indigo), and ACCEL (orange) subsets.

(weak interaction cases). Strong and weak interactions are more likely to be part of the DECEL and ACCEL subsets, respectively. The detailed lists of TC-trough interactions belonging to each subset can be found in Tables S1 and S2 [the lists of strong and weak interactions are taken from Archambault et al. (2013)]. Furthermore, DECEL troughs are also associated with lower values of negative PV advection by the irrotational wind than in ACCEL, when averaging in time and space around $t_{\mathrm{ET}}$ as in Archambault et al. (2013; Fig. 12).

A more refined PV advection budget is performed to better relate trough deceleration to the action of diabatic processes. After partitioning the wind field at $350 \mathrm{~K}$ in its irrotational and nondivergent components, $\mathrm{PV}$ advection is averaged in a $15^{\circ} \times 15^{\circ}$ box centered at the position of the trough $\mathrm{CM}$ at each time step. This solution is preferred to the choice of a geographically fixed box, as it better highlights the evolution of PV advection during TC-trough interaction and avoids that rapidly moving troughs cross and exit the area during time averaging. The difference between the two subsets is particularly large in the time steps preceding $t_{\mathrm{ET}}$ (Fig. 13a). The period between $t_{\mathrm{ET}}-24 \mathrm{~h}$ and $t_{\mathrm{ET}}$ also corresponds to the strongest trough deceleration in DECEL (see Fig. 4b). A direct relationship between PV advection by the irrotational wind and trough deceleration can be inferred, following Hoskins et al. (1985): the diabatically influenced negative PV anomaly

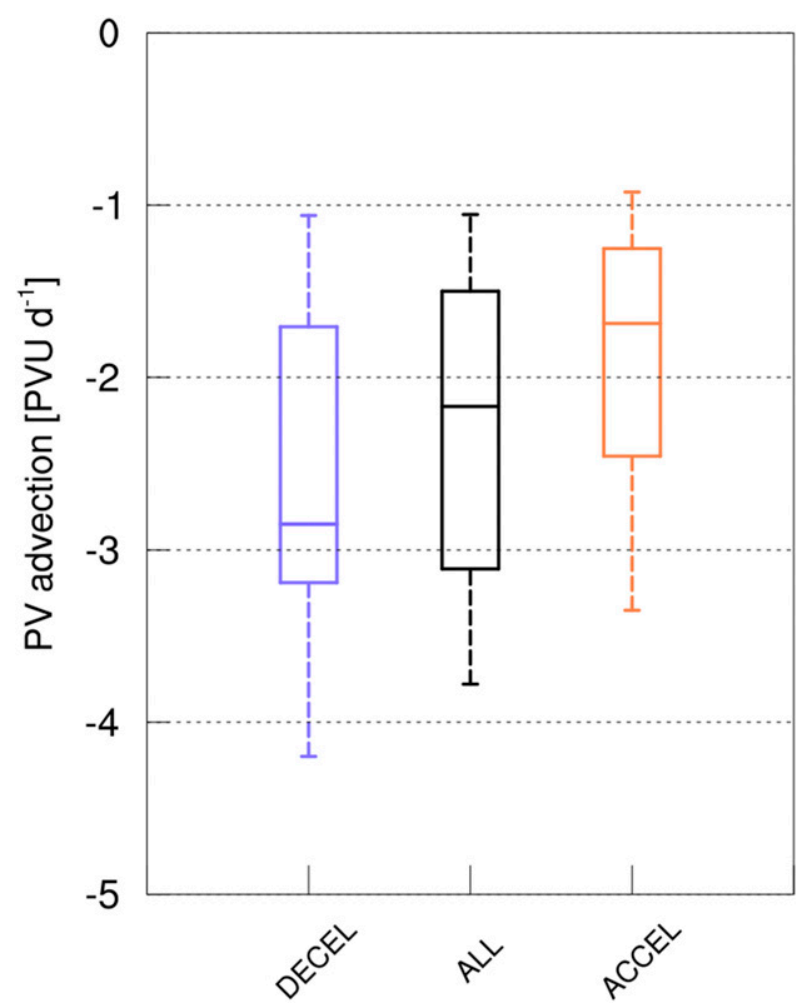

FIG. 12. Distributions of PV advection by the irrotational wind for the DECEL (indigo), ALL (black), and ACCEL (orange) subsets, averaged in the isentropic layer $345-355 \mathrm{~K}$ between $t_{\mathrm{ET}}-$ $24 \mathrm{~h}$ and $t_{\mathrm{ET}}+24 \mathrm{~h}$ in a $15^{\circ} \times 15^{\circ}$ area centered at the location of maximum interaction. Box-and-whisker diagrams as in Fig. 2.

at the waveguide, related to the low-PV irrotational outflow, can hinder the eastward propagation of the upstream trough while causing its meridional elongation.

Negative PV advection by the irrotational wind is more pronounced in DECEL than in ACCEL (Figs. 13d,g): this is due to the stronger irrotational wind related to latent heat release in clouds (not shown), as hinted by the accumulated precipitation to the north of the transitioning TC. PV advection by the remaining, nondivergent component of the wind field is similar between the subsets before $t_{\mathrm{ET}}$ (Fig. 13b). The nondivergent flow advects the trough eastward and is therefore related to an area of positive $\mathrm{PV}$ advection at the right side of the trough, as air with higher PV moves toward an area previously occupied by the low-PV ridge. This component of $\mathrm{PV}$ advection has similar strength in DECEL and ACCEL (Figs. 13e,h). The eastward propagation of the trough is dictated by the sum of PV advection by the two wind components. The lower part of the trough is collocated with positive PV advection in DECEL, whereas the upper part is collocated with negative PV advection: this pattern 
(a) PV advection by the irrotational wind

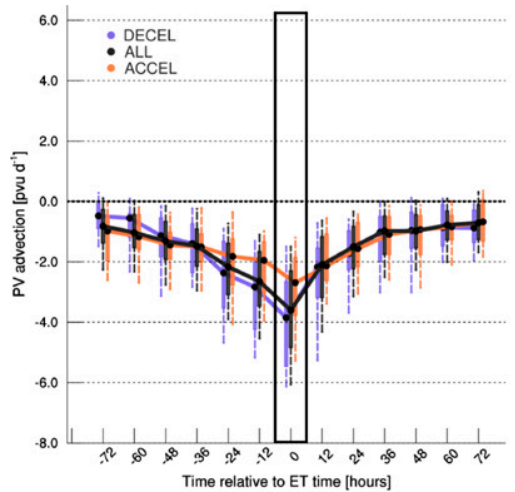

(d) DECEL - Irrotational wind

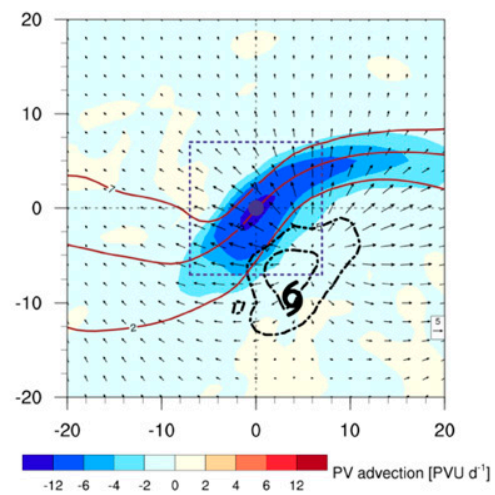

(g) ACCEL - Irrotational wind

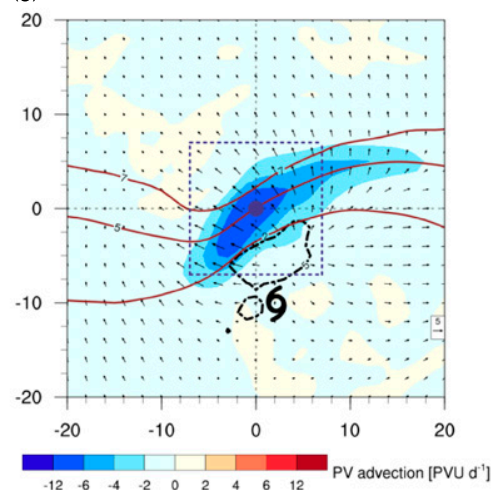

(b) PV advection by the nondivergent wind

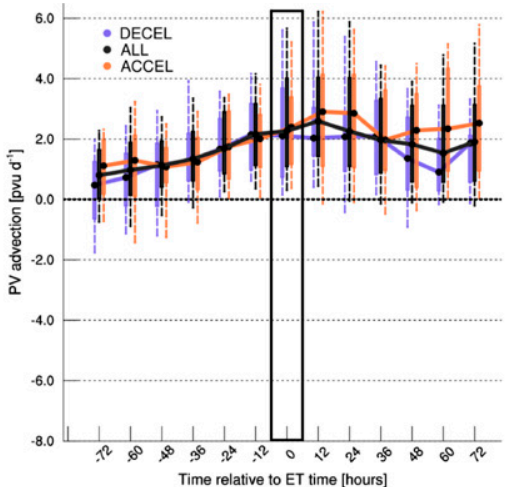

(e) DECEL - Nondivergent wind

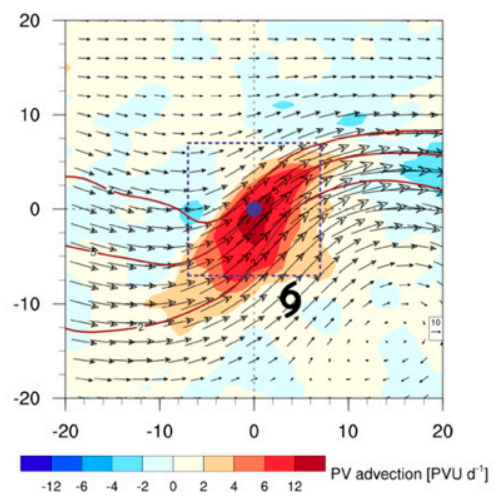

(h) ACCEL - Nondivergent wind

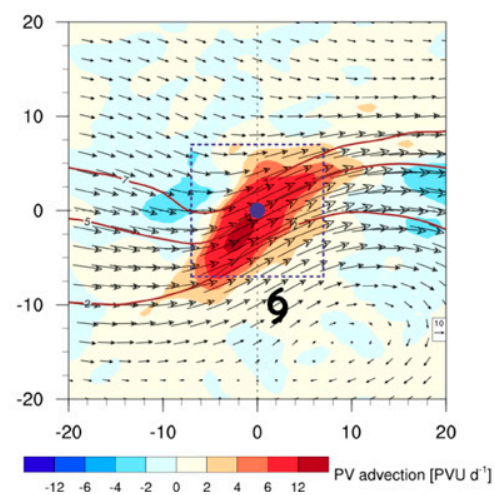

(c) Total PV advection

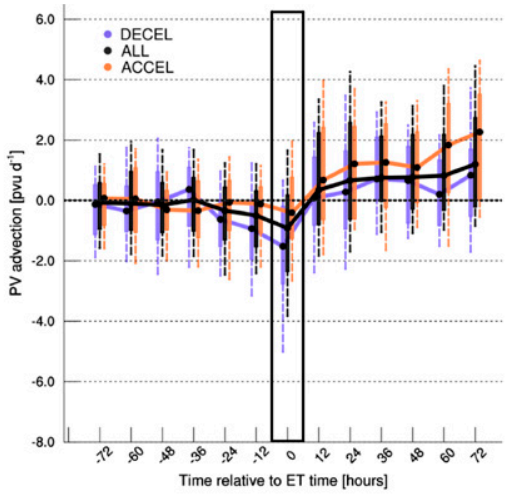

(f) DECEL - Full wind

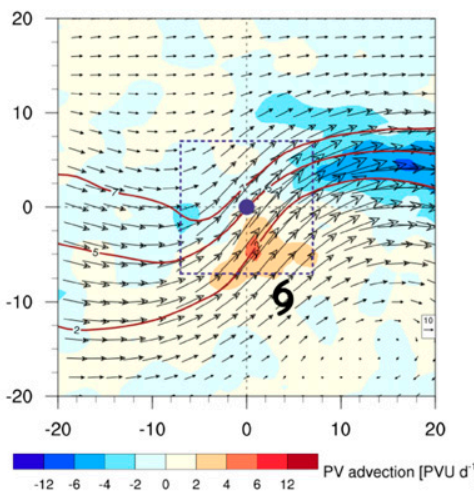

$\begin{array}{cccccc}-12 & -6 & -4 & -2 & 0 & 2 \\ A C C E L & - \text { Full wind }\end{array}$

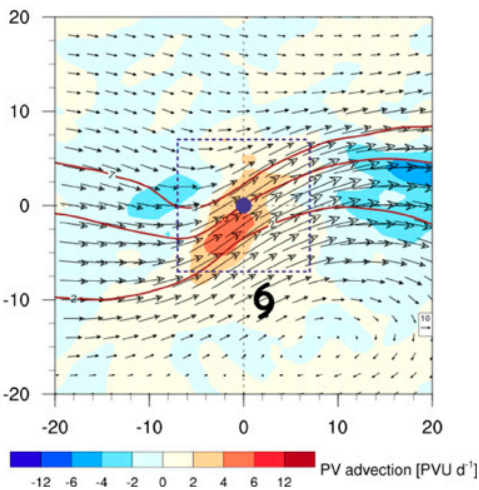

FIG. 13. (a)-(c) Time series of the distributions of averaged PV advection by the (a) irrotational, (b) nondivergent component of the wind, and (c) total wind relative to $t_{\mathrm{ET}}$. DECEL (ACCEL) TC-trough interactions are colored in indigo (orange), while the values relative to the $N=195$ TCs of the ALL subset are colored in black. Box-and-whisker diagrams as in Fig. 2. (d)-(j) Trough $\mathrm{CM}$-centered composites at $t_{\mathrm{ET}}$ of PV advection by the irrotational, nondivergent, and full component of the wind (wind vectors) for (d)-(f) DECEL and (g),(h),(j) ACCEL. The blue dashed square contour indicates the regions around trough CM (blue dot at the origin) where areal averaging of PV advection was performed to obtain the time series in (a)-(c). Composites of PV at $350 \mathrm{~K}$ (bold brown contours) and total precipitation in DECEL [black dashed contours in (d),(g); only 5 and $10 \mathrm{~mm} 6 \mathrm{~h}^{-1}$ ] at $t_{\mathrm{ET}}$ are overlaid.

promotes a further meridional elongation of the trough and supports ridge building directly at its eastern flank (Fig. 13f). On the other hand, an area of positive PV advection occupies the area of strong PV gradient in ACCEL, indicating that the trough keeps moving eastward, and a much weaker negative PV advection is present downstream, suggesting weaker ridge building (Fig. 13j).

\section{f. Far-downstream effects: Atmospheric blocking}

It has been shown that the presence of TC-trough interactions is associated with an increased likelihood over 
the North Pacific (see section 3a). However, this response is also strongly modulated by the occurrence of phase locking.

A large part of the observed increase in blocking frequency over the eastern North Pacific for the ALL subset (Fig. 3) is related to the DECEL subset. The presence of high-amplitude RWPs over the region makes atmospheric blocking up to 3 times more frequent than climatology in the 1-5 days following $t_{\mathrm{ET}}$ (Fig. 14; note the different color scale than Fig. 3). On the other hand, ACCEL cases do not exhibit marked differences from climatology before and after $t_{\mathrm{ET}}$ (Fig. 15), except over Greenland 7-10 days after $t_{\mathrm{ET}}$.

The planetary wave pattern strongly influences where the genesis of atmospheric blocking occurs. It still needs to be assessed whether significant differences in planetary-scale flow, which could be related to the different observed blocking patterns, exist between ACCEL and DECEL. For instance, the presence of significantly positive $\Delta f_{B}$ over northeastern Canada already before and around $t_{\mathrm{ET}}$ (Figs. 14a,b), together with significantly positive and negative $\Delta f_{B}$ over Greenland in the following days (Figs. 14c,d), may indicate that a planetary Rossby wave pattern favoring or hindering atmospheric blocking at mid- and high latitudes is already in place during DECEL cases.

\section{g. Final remarks}

- The presence of track bifurcation with respect to the upstream trough (Fig. 8b) corroborates from a climatological point of view the hypotheses of Scheck et al. (2011b), Grams et al. (2013a), and Riemer and Jones (2014) regarding the presence of hyperbolic stagnation points and track bifurcation during ET. In summary, TCs that are recurving not only in a geographical sense, but also in a trough-relative frame of reference, are related to a significant downstream impact on the midlatitude flow.

- It is not yet clear whether trough deceleration is mostly due to the described adiabatic or diabatic processes. The upstream trough in DECEL, which is more meridionally extended than in ACCEL already before $t_{\mathrm{ET}}$ (Figs. $6 \mathrm{~d}-\mathrm{f}$ ), may also be more prone to deceleration and to the onset of phase locking. Conversely, the strong irrotational winds related to latent heat release may have a primary influence in initially decelerating the trough and in inducing phase locking. The performed analysis shows that these two processes are both present, but their relative importance is most likely case dependent. It should be kept in mind that the effect of diabatic processes on trough deceleration and ridge building is intertwined with the effect of "adiabatic" processes like baroclinic development: these two components cooperate synergistically, and it is difficult to clearly separate their contributions to the downstream impact of ET (e.g., Archambault et al. 2015).

- A detailed analysis of the impact of the mean state on atmospheric blocking downstream of ET lies outside the scope of the current study. Low-frequency modes as ENSO, the Madden-Julian oscillation (MJO), or the Pacific-North American pattern may also influence the mean circulation pattern over the North Pacific (see, e.g., Cordeira and Bosart 2010; Henderson et al. 2016), and their effect also needs to be evaluated. However, it can be concluded from the current study that some types of ET in the western North Pacific are significantly more related than others to blocking over the western portion of the North American continent.

\section{Conclusions and outlook}

A set of 195 TC-trough interactions in the western North Pacific during ASO between 1979 and 2013 has been analyzed to understand how characteristics of the midlatitude flow modulate the downstream impact of recurving TCs. Confirming previous results, such interactions lead to significantly enhanced RWP amplitude over the North Pacific in the 2-5 days following ET. Additionally, TC recurvature in the western North Pacific is significantly correlated in the same time frame with positive deviations in blocking frequency over the central and eastern North Pacific.

We have developed and applied a trough-tracking algorithm to study changes in the zonal phase speed of troughs during the interaction with recurving TCs. Specifically, a substantial deceleration of troughs indicates phase locking. Most of the troughs featured such a deceleration: however, $1 / 4$ of the considered troughs (the ACCEL subset; 49 cases) did not decelerate during the interaction with a recurving TC. This subset of troughs was compared with the one featuring the strongest deceleration (the DECEL subset; also 49 cases) to understand the differences in phasing, downstream impact, and blocking activity.

DECEL cases featured troughs that remained upstream of the TC during the interaction, exhibited phase locking, and were associated with a higher downstream RWP amplitude than average. On the other hand, ACCEL TCs already were overtaken by the approaching trough $24 \mathrm{~h}$ after $t_{\mathrm{ET}}$, did not exhibit phase locking, and were associated with a response that was not significantly different from the climatology. 
(a) DECEL $t_{E T-1}$ d

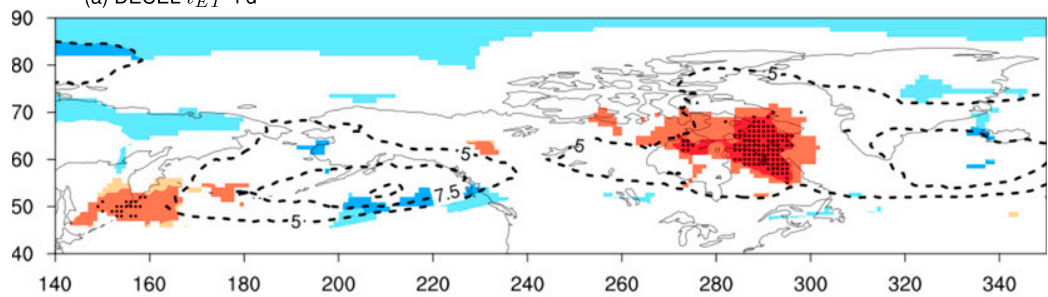

(b) DECEL $t_{E T+1 \mathrm{~d}}$

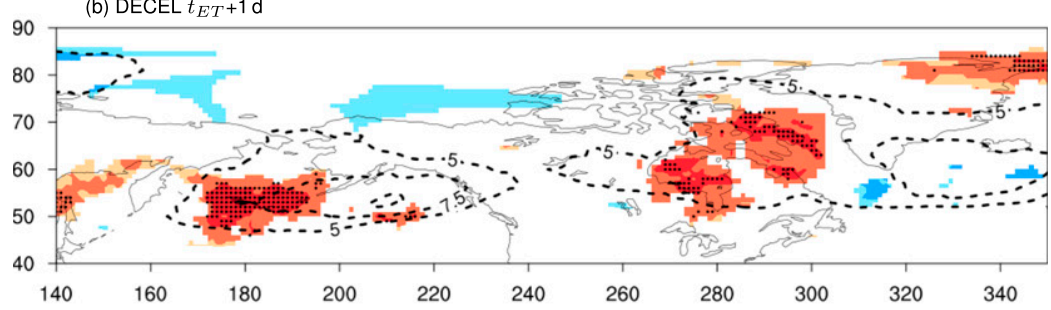

(c) DECEL $t_{E T}+3 \mathrm{~d}$
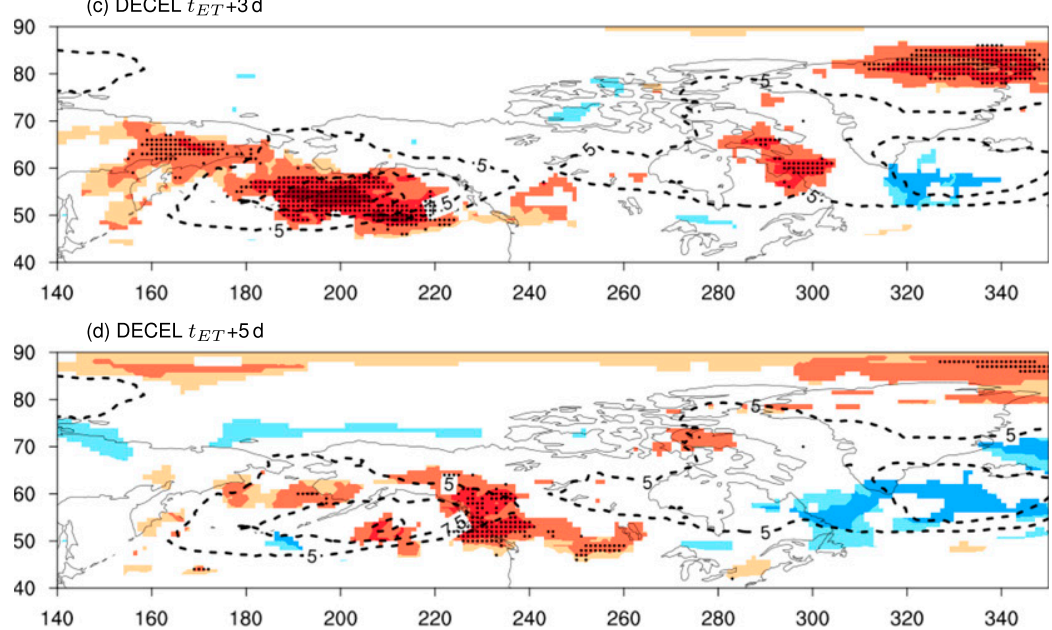

(e) DECEL $t_{E T}+7 \mathrm{~d}$
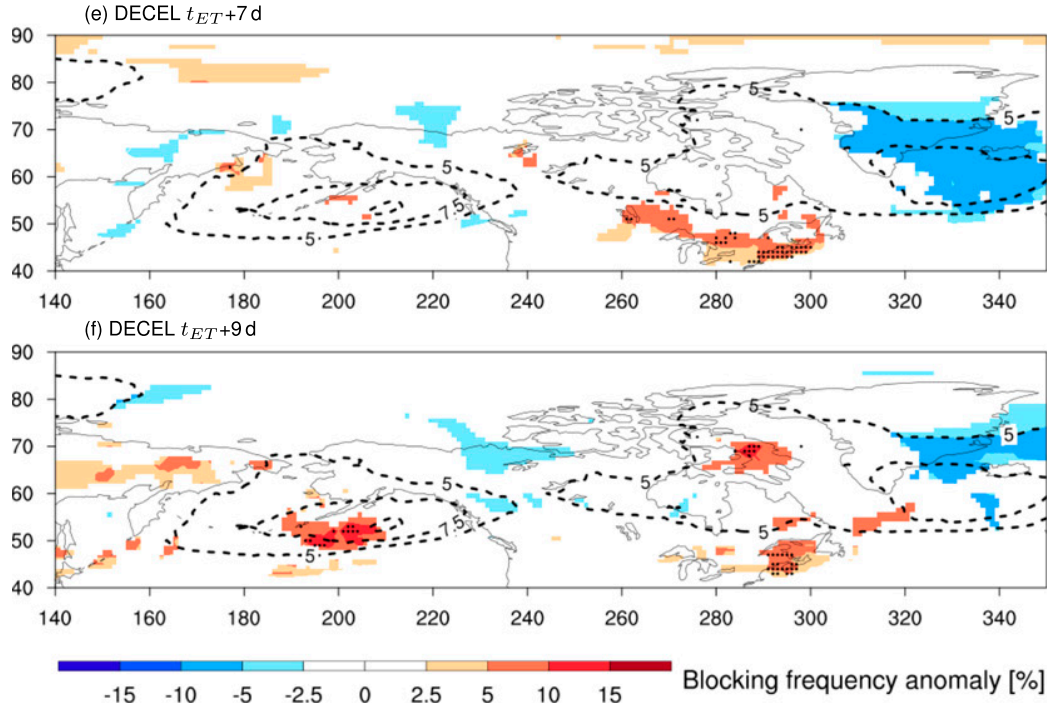

FIG. 14. As in Fig. 3, but for the $N=49$ recurving TCs in the DECEL subset. 
(a) ACCEL $t_{E T^{-1}} \mathrm{~d}$
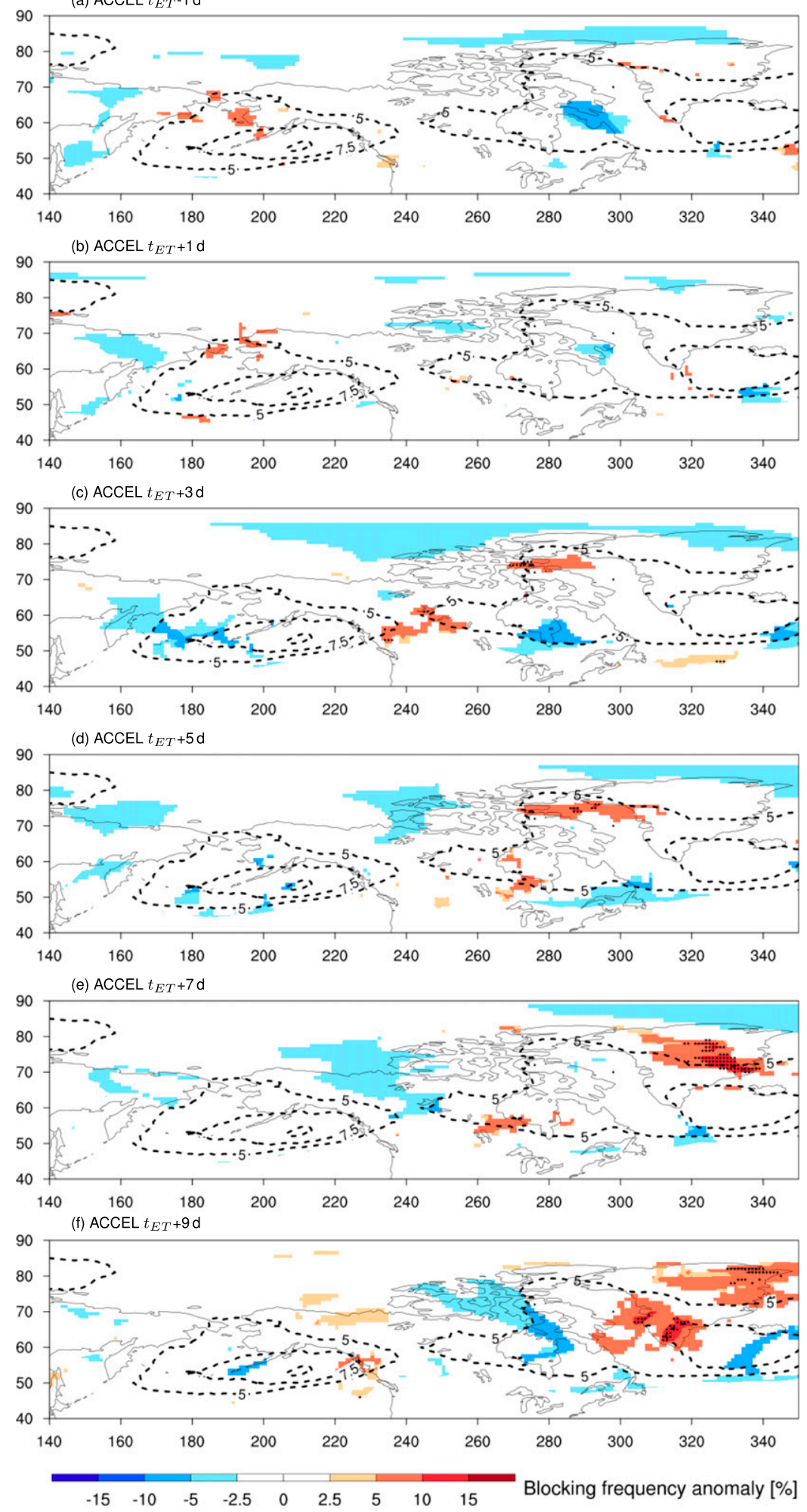

FIG. 15. As in Fig. 3, but for the $N=49$ recurving TCs in the ACCEL subset. 
We conclude that to a first order, phase locking between the TC and the upper-level trough can explain the observed variability in downstream impact of ET. Two contributions to downstream impact are highlighted in this study. The "adiabatic" contribution is based on the classical concept of interplay between an upper-level PV anomaly (the trough) and a lower-level potential temperature anomaly (related to the transitioning TC), favored by the presence of strong cyclogenetic forcing for ascent. The "diabatic" contribution highlights the role of the irrotational outflow from diabatic processes in enhancing ridge building during ET and in inducing trough deceleration, which supports the subsequent phase locking.

The different downstream impact is closely related to the occurrence of atmospheric blocking over the North Pacific. DECEL cases featured blocking even more frequently than the average TC-trough interaction, while the frequency of atmospheric blocking downstream of ACCEL cases was not significantly different from climatology. Given that latent heat release and irrotational outflow during TC-trough interaction were stronger in DECEL than in ACCEL, the described differences in blocking activity further support hypotheses relative to the importance of ET (and more generally of upstream diabatic processes) in modulating atmospheric blocking activity (Small et al. 2014; Pfahl et al. 2015).

The limitations of the present study are discussed in the following, together with possible future directions. The employed RWP amplitude metric may give an underestimation of the meridional amplitude of the midlatitude flow in configurations of Rossby wave breaking and does not take into account the semigeostrophic nature of Rossby waves (see Wolf and Wirth 2015, 2017). Sensitivity studies are still needed to understand in detail the synergistic interplay between the adiabatic and diabatic processes: for instance, the framework of Teubler and Riemer (2016) would be useful to understand the role of divergent, diabatic, and barotropic components in the generation of the PV anomaly. The eddy kinetic energy framework (e.g., Keller et al. 2014; Quinting and Jones 2016; Keller 2017) can be employed to complement this view and to assess whether the presence of trough deceleration depends also on the structure of the waveguide at $t_{\mathrm{ET}}$ (e.g., strength of $\mathrm{PV}$ gradient/background flow). Another future research path could consist of assessing whether a similar sort of phasing can be relevant for the downstream impact of extratropical cyclones, also from the point of view of medium-range predictability (e.g., Torn 2017). Analysis of other basins could also be performed: for instance, given that significant anomalies of RWP amplitude downstream of recurving TCs in the North Atlantic are less evident (Torn and Hakim 2015; Quinting and Jones 2016), phasing can modulate downstream impact even more strongly in that basin than in the western North Pacific. Finally, the characteristics of atmospheric blocking downstream of ET need to be evaluated in a more systematic study. Given the relationship between atmospheric blocking and extreme weather over the midlatitudes, it would be interesting to investigate the link between TCtrough interaction and high-impact weather over North America in the following 5-10 days. A preliminary assessment, focused on cases featuring a particularly strong negative PV advection by the irrotational wind, was performed by Archambault et al. (2014).

In conclusion, the current study confirms from a climatological perspective that trough deceleration during ET is actually related to an enhanced downstream impact, due to the occurrence of phase locking and to the synergistic interaction between adiabatic and diabatic processes.

Acknowledgments. The suggestions of three anonymous reviewers were very useful to improve the quality and the readability of the manuscript. We are grateful to Heini Wernli and Ron McTaggart-Cowan for discussing an earlier version of the manuscript and for the support in writing and revising it. We thank Julian Quinting for providing the algorithm of the Zimin et al. (2006) RWP diagnostics, Maxi Boettcher for the Q-vector inversion algorithm, and Michael Sprenger for the technical support. We also thank the Atmospheric Dynamics group at ETH Zurich for discussing technical issues and supporting in the interpretation of the results. The work of JR is supported by the ETH Zurich Foundation, in collaboration with Coop (ETH Research Grant 1014-1). The contribution of CMG was supported by the Swiss National Science Foundation (SNSF) Grant PZ00P2_148177/1 and completed while he holds a Young Investigator Group grant by the German Helmholtz Association (VH-NG1243). MR acknowledges funding from the subproject "A4: Evolution and predictability of storm structure during extratropical transition of tropical cyclones" of the Transregional Collaborative Research Center SFB/TRR 165 "Waves to Weather" program funded by the German Science Foundation (DFG).

\section{REFERENCES}

Agustí-Panareda, A., 2008: The contribution of ex-Tropical Cyclone Gert (1999) toward the weakening of a midlatitude cyclogenesis event. Mon. Wea. Rev., 136, 2091-2111, https://doi.org/10.1175/ 2007MWR1637.1.

— S. L. Gray, G. C. Craig, and C. D. Thorncroft, 2005: The extratropical transition of Tropical Cyclone Lili (1996) and its crucial contribution to a moderate extratropical development. Mon. Wea. Rev., 133, 1562-1573, https://doi.org/10.1175/MWR2935.1.

Altenhoff, A. M., O. Martius, M. Croci-Maspoli, C. Schwierz, and H. C. Davies, 2008: Linkage of atmospheric blocks and synoptic-scale 
Rossby waves: A climatological analysis. Tellus, 60A, 1053-1063, https://doi.org/10.1111/j.1600-0870.2008.00354.x.

Archambault, H. M., L. F. Bosart, D. Keyser, and J. M. Cordeira, 2013: A climatological analysis of the extratropical flow response to recurving western North Pacific tropical cyclones. Mon. Wea. Rev., 141, 2325-2346, https://doi.org/10.1175/ MWR-D-12-00257.1.

_ , P. A. Harr, and R. W. Moore, 2014: Recurving tropical cyclones as precursors to blocking. 31st Conf. on Hurricanes and Tropical Meteorology, San Diego, CA, Amer. Meteor. Soc., 169, https:// ams.confex.com/ams/31Hurr/webprogram/Paper245269.html.

_ D. Keyser, L. F. Bosart, C. A. Davis, and J. M. Cordeira, 2015: A composite perspective of the extratropical flow response to recurving western North Pacific tropical cyclones. Mon. Wea. Rev., 143, 1122-1141, https://doi.org/10.1175/MWR-D-14-00270.1.

Atallah, E. H., and L. F. Bosart, 2003: The extratropical transition and precipitation distribution of Hurricane Floyd (1999). Mon. Wea. Rev., 131, 1063-1081, https://doi.org/10.1175/15200493(2003)131<1063:TETAPD>2.0.CO;2.

Barton, Y., P. Giannakaki, H. von Waldow, C. Chevalier, S. Pfahl, and O. Martius, 2016: Clustering of regional-scale extreme precipitation events in southern Switzerland. Mon. Wea. Rev., 144, 347-369, https://doi.org/10.1175/MWR-D-15-0205.1.

Berry, G., C. Thorncroft, and T. Hewson, 2007: African easterly waves during 2004-Analysis using objective techniques. Mon. Wea. Rev., 135, 1251-1267, https://doi.org/ 10.1175/MWR3343.1.

Binder, H., M. Boettcher, H. Joos, and H. Wernli, 2016: The role of warm conveyor belts for the intensification of extratropical cyclones in Northern Hemisphere winter. J. Atmos. Sci., 73, 3997-4020, https://doi.org/10.1175/JAS-D-15-0302.1.

Bosart, L. F., and G. M. Lackmann, 1995: Postlandfall tropical cyclone reintensification in a weakly baroclinic environment: A case study of Hurricane David (September 1979). Mon. Wea. Rev., 123, 3268-3291, https://doi.org/10.1175/1520-0493(1995) $123<3268$ :PTCRIA $>2.0$. CO;2.

Čampa, J., and H. Wernli, 2012: A PV perspective on the vertical structure of mature midlatitude cyclones in the Northern Hemisphere. J. Atmos. Sci., 69, 725-740, https://doi.org/ 10.1175/JAS-D-11-050.1.

Cordeira, J. M., and L. F. Bosart, 2010: The antecedent large-scale conditions of the "perfect storms" of late October and early November 1991. Mon. Wea. Rev., 138, 2546-2569, https://doi.org/ 10.1175/2010MWR3280.1.

Coronel, B., D. Ricard, G. Rivière, and P. Arbogast, 2015: Role of moist processes in the tracks of idealized midlatitude surface cyclones. J. Atmos. Sci., 72, 2979-2996, https://doi.org/10.1175/ JAS-D-14-0337.1.

Crezee, B., H. Joos, and H. Wernli, 2017: The microphysical building blocks of low-level potential vorticity anomalies in an idealized extratropical cyclone. J. Atmos. Sci., 74, 1403-1416, https://doi.org/10.1175/JAS-D-16-0260.1.

Davies, H. C., 2015: The quasigeostrophic omega equation: Reappraisal, refinements, and relevance. Mon. Wea. Rev., 143, 3-25, https://doi.org/10.1175/MWR-D-14-00098.1.

Davis, C. A., M. T. Stoelinga, and Y.-H. Kuo, 1993: The integrated effect of condensation in numerical simulations of extratropical cyclogenesis. Mon. Wea. Rev., 121, 2309-2330, https://doi.org/ 10.1175/1520-0493(1993)121<2309:TIEOCI >2.0.CO;2.

Dee, D. P., and Coauthors, 2011: The ERA-Interim reanalysis: Configuration and performance of the data assimilation system. Quart. J. Roy. Meteor. Soc., 137, 553-597, https://doi.org/ 10.1002/qj.828.
Evans, J. L., and R. E. Hart, 2003: Objective indicators of the life cycle evolution of extratropical transition for Atlantic tropical cyclones. Mon. Wea. Rev., 131, 909-925, https://doi.org/ 10.1175/1520-0493(2003)131<0909:OIOTLC $>2.0 . C O ; 2$.

Grams, C. M., and H. M. Archambault, 2016: The key role of diabatic outflow in amplifying the midlatitude flow: A representative case study of weather systems surrounding western North Pacific extratropical transition. Mon. Wea. Rev., 144, 3847-3869, https://doi.org/10.1175/MWR-D-15-0419.1.

, S. C. Jones, and C. A. Davis, 2013a: The impact of Typhoon Jangmi (2008) on the midlatitude flow. Part II: Downstream evolution. Quart. J. Roy. Meteor. Soc., 139, 2165-2180, https:// doi.org/10.1002/qj.2119.

,,,--- P. A. Harr, and M. Weissmann, 2013b: The impact of Typhoon Jangmi (2008) on the midlatitude flow. Part I: Upper-level ridgebuilding and modification of the jet. Quart. J. Roy. Meteor. Soc., 139, 2148-2164, https://doi.org/10.1002/ qj.2091.

Harr, P. A., and J. M. Dea, 2009: Downstream development associated with the extratropical transition of tropical cyclones over the western North Pacific. Mon. Wea. Rev., 137, 12951319, https://doi.org/10.1175/2008MWR2558.1.

_, R. L. Elsberry, and T. F. Hogan, 2000: Extratropical transition of tropical cyclones over the western North Pacific. Part II: The impact of midlatitude circulation characteristics. Mon. Wea. Rev., 128, 2634-2653, https://doi.org/10.1175/1520-0493(2000) $128<2634$ :ETOTCO $>2.0$. CO; 2 .

Henderson, S. A., E. D. Maloney, and E. A. Barnes, 2016: The influence of the Madden-Julian oscillation on Northern Hemisphere winter blocking. J. Climate, 29, 4597-4616, https://doi.org/10.1175/JCLI-D-15-0502.1.

Hodyss, D., and E. Hendricks, 2010: The resonant excitation of baroclinic waves by the divergent circulation of recurving tropical cyclones. J. Atmos. Sci., 67, 3600-3616, https://doi.org/ 10.1175/2010JAS3459.1.

Hoskins, B. J., M. E. McIntyre, and A. W. Robertson, 1985: On the use and significance of isentropic potential vorticity maps. Quart. J. Roy. Meteor. Soc., 111, 877-946, https://doi.org/ 10.1002/qj.49711147002.

Jones, S. C., and Coauthors, 2003: The extratropical transition of tropical cyclones: Forecast challenges, current understanding, and future directions. Wea. Forecasting, 18, 1052-1092, https:// doi.org/10.1175/1520-0434(2003)018<1052:TETOTC>2.0.CO;2.

Joos, H., and H. Wernli, 2012: Influence of microphysical processes on the potential vorticity development in a warm conveyor belt: A case-study with the limited-area model COSMO. Quart. J. Roy. Meteor. Soc., 138, 407-418, https://doi.org/ 10.1002/qj.934.

Keller, J. H., 2017: Amplification of the downstream wave train during extratropical transition: Sensitivity studies. Mon. Wea. Rev., 145, 1529-1548, https://doi.org/10.1175/MWR-D-16-0193.1.

— S. C. Jones, and P. A. Harr, 2014: An eddy kinetic energy view of physical and dynamical processes in distinct forecast scenarios for the extratropical transition of two tropical cyclones. Mon. Wea. Rev., 142, 2751-2771, https://doi.org/ 10.1175/MWR-D-13-00219.1.

_ , and Coauthors, 2019: The extratropical transition of tropical cyclones. Part II: Interaction with the midlatitude flow, downstream impacts, and implications in predictability. Mon. Wea. Rev., https://doi.org/10.1175/MWR-D-17-0329.1, in press.

Keyser, D., B. D. Schmidt, and D. G. Duffy, 1992: Quasigeostrophic vertical motions diagnosed from along- and crossisentrope components of the $\mathrm{Q}$ vector. Mon. Wea. Rev., 120, 
731-741, https://doi.org/10.1175/1520-0493(1992)120<0731: QVMDFA $>2.0 . C O ; 2$.

Klein, P. M., P. A. Harr, and R. L. Elsberry, 2000: Extratropical transition of western North Pacific tropical cyclones: An overview and conceptual model of the transformation stage. Wea. Forecasting, 15, 373-395, https://doi.org/10.1175/15200434(2000)015<0373:ETOWNP > 2.0.CO;2.

\section{, —, and -2002 : Extratropical transition of western} North Pacific tropical cyclones: Midlatitude and tropical cyclone contributions to reintensification. Mon. Wea. Rev., 130, 2240-2259, https://doi.org/10.1175/1520-0493(2002)130<2240: ETOWNP $>2.0 . \mathrm{CO} ; 2$.

Knaff, J. A., 2009: Revisiting the maximum intensity of recurving tropical cyclones. Int. J. Climatol., 29, 827-837, https://doi.org/ 10.1002/joc.1746.

Knapp, K. R., M. C. Kruk, D. H. Levinson, H. J. Diamond, and C. J. Neumann, 2010: The International Best Track Archive for Climate Stewardship (IBTrACS): Unifying tropical cyclone data. Bull. Amer. Meteor. Soc., 91, 363-376, https://doi.org/ 10.1175/2009BAMS2755.1.

Martin, J. E., 2006: The role of shearwise and transverse quasigeostrophic vertical motions in the midlatitude cyclone life cycle. Mon. Wea. Rev., 134, 1174-1193, https://doi.org/10.1175/ MWR3114.1.

, 2007: Lower-tropospheric height tendencies associated with the shearwise and transverse components of quasigeostrophic vertical motion. Mon. Wea. Rev., 135, 2803-2809, https://doi.org/ 10.1175/MWR3416.1.

Masato, G., B. J. Hoskins, and T. J. Woollings, 2012: Wave-breaking characteristics of midlatitude blocking. Quart. J. Roy. Meteor. Soc., 138, 1285-1296, https://doi.org/10.1002/qj.990.

McTaggart-Cowan, R., J. R. Gyakum, and M. K. Yau, 2001: Sensitivity testing of extratropical transitions using potential vorticity inversions to modify initial conditions: Hurricane Earl case study. Mon. Wea. Rev., 129, 1617-1636, https://doi.org/10.1175/ 1520-0493(2001)129<1617:STOETU>2.0.CO;2.

,-- , and 2004: The impact of tropical remnants on extratropical cyclogenesis: Case study of Hurricanes Danielle and Earl (1998). Mon. Wea. Rev., 132, 1933-1951, https://doi.org/ 10.1175/1520-0493(2004)132<1933:TIOTRO>2.0.CO;2.

_ L. F. Bosart, J. R. Gyakum, and E. H. Atallah, 2007a: Hurricane Katrina (2005). Part I: Complex life cycle of an intense tropical cyclone. Mon. Wea. Rev., 135, 3905-3926, https://doi.org/10.1175/ 2007MWR1875.1.

, — $—$, and — 2007b: Hurricane Katrina (2005). Part II: Evolution and hemispheric impacts of a diabatically generated warm pool. Mon. Wea. Rev., 135, 3927-3949, https://doi.org/ 10.1175/2007MWR2096.1.

Pantillon, F., J. P. Chaboureau, C. Lac, and P. Mascart, 2013: On the role of a Rossby wave train during the extratropical transition of Hurricane Helene (2006). Quart. J. Roy. Meteor. Soc., 139, 370-386, https://doi.org/10.1002/qj.1974.

,-- , and E. Richard, 2016: Vortex-vortex interaction between Hurricane Nadine (2012) and an Atlantic cut-off dropping the predictability over the Mediterranean. Quart. J. Roy. Meteor. Soc., 142, 419-432, https://doi.org/10.1002/ qj. 2635.

Pfahl, S., C. Schwierz, M. Croci-Maspoli, C. M. Grams, and H. Wernli, 2015: Importance of latent heat release in ascending air streams for atmospheric blocking. Nat. Geosci., 8 , 610-614, https://doi.org/10.1038/ngeo2487.

Pomroy, H. R., and A. J. Thorpe, 2000: The evolution and dynamical role of reduced upper-tropospheric potential vorticity in Intensive
Observing Period One of FASTEX. Mon. Wea. Rev., 128, 1817-1834, https://doi.org/10.1175/1520-0493(2000)128<1817: TEADRO $>2.0 . \mathrm{CO} ; 2$.

Quinting, J. F., and S. C. Jones, 2016: On the impact of tropical cyclones on Rossby wave packets: A climatological perspective. Mon. Wea. Rev., 144, 2021-2048, https://doi.org/10.1175/ MWR-D-14-00298.1.

Rex, D. F., 1950: Blocking action in the middle troposphere and its effect upon regional climate. II: The climatology of blocking action. Tellus, 2, 275-301, https://doi.org/10.1111/j.21533490.1950.tb00339.x.

Riboldi, J., M. Röthlisberger, and C. M. Grams, 2018: Rossby wave initiation by recurving tropical cyclones in the western North Pacific. Mon. Wea. Rev., 146, 1283-1301, https://doi.org/ 10.1175/MWR-D-17-0219.1.

Riemer, M., and S. C. Jones, 2010: The downstream impact of tropical cyclones on a developing baroclinic wave in idealized scenarios of extratropical transition. Quart. J. Roy. Meteor. Soc., 136, 617-637, https://doi.org/10.1002/qj.605.

— and - 2014: Interaction of a tropical cyclone with a highamplitude, midlatitude wave pattern: Waviness analysis, trough deformation and track bifurcation. Quart. J. Roy. Meteor. Soc., 140, 1362-1376, https://doi.org/10.1002/qj.2221.

,-- , and C. A. Davis, 2008: The impact of extratropical transition on the downstream flow: An idealized modelling study with a straight jet. Quart. J. Roy. Meteor. Soc., 134, 6991, https://doi.org/10.1002/qj.189.

_ , M. Baumgart, and S. Eiermann, 2014: Cyclogenesis downstream of extratropical transition analyzed by Q-vector partitioning based on flow geometry. J. Atmos. Sci., 71, 4204-4220, https://doi.org/10.1175/JAS-D-14-0023.1.

Ritchie, E. A., and R. L. Elsberry, 2003: Simulations of the extratropical transition of tropical cyclones: Contributions by the midlatitude upper-level trough to reintensification. Mon. Wea. Rev., 131, 2112-2128, https://doi.org/10.1175/1520-0493(2003)131<2112: SOTETO $>2.0 . \mathrm{CO} ; 2$.

$\longrightarrow$, and - 2007: Simulations of the extratropical transition of tropical cyclones: Phasing between the upper-level trough and tropical cyclones. Mon. Wea. Rev., 135, 862-876, https://doi.org/ 10.1175/MWR3303.1.

Scheck, L., S. C. Jones, and M. Juckes, 2011a: The resonant interaction of a tropical cyclone and a tropopause front in a barotropic model. Part I: Zonally oriented front. J. Atmos. Sci., 68, 405-419, https://doi.org/10.1175/2010JAS3482.1.

,$- \ldots$, and — 2011b: The resonant interaction of a tropical cyclone and a tropopause front in a barotropic model. Part II: Frontal waves. J. Atmos. Sci., 68, 420-429, https://doi.org/ 10.1175/2010JAS3483.1.

Schwierz, C., M. Croci-Maspoli, and H. C. Davies, 2004: Perspicacious indicators of atmospheric blocking. Geophys. Res Lett., 31, L06125, https://doi.org/10.1029/2003GL019341.

Small, D., E. Atallah, and J. R. Gyakum, 2014: An objectively determined blocking index and its Northern Hemisphere climatology. J. Climate, 27, 2948-2970, https://doi.org/10.1175/ JCLI-D-13-00374.1.

Stoelinga, M. T., 1996: A potential vorticity-based study of the role of diabatic heating and friction in a numerically simulated baroclinic cyclone. Mon. Wea. Rev., 124, 849-874, https://doi.org/ 10.1175/1520-0493(1996)124<0849:APVBSO > 2.0.CO;2.

Studholme, J., K. I. Hodges, and C. M. Brierley, 2015: Objective determination of the extratropical transition of tropical cyclones in the Northern Hemisphere. Tellus, 67A, 24474, https://doi.org/10.3402/tellusa.v67.24474. 
Teubler, F., and M. Riemer, 2016: Dynamics of Rossby wave packets in a quantitative potential vorticity-potential temperature framework. J. Atmos. Sci., 73, 1063-1081, https://doi.org/ 10.1175/JAS-D-15-0162.1.

Torn, R. D., 2017: A comparison of the downstream predictability associated with ET and baroclinic cyclones. Mon. Wea. Rev. 145, 4651-4672, https://doi.org/10.1175/MWR-D-17-0083.1.

_ ated with extratropical transition and winter cyclones. Mon. Wea. Rev., 143, 1782-1803, https://doi.org/10.1175/MWR-D14-00006.1.

_ - J. S. Whitaker, P. Pegion, T. M. Hamill, and G. J. Hakim, 2015: Diagnosis of the source of GFS medium-range track errors in Hurricane Sandy (2012). Mon. Wea. Rev., 143, 132152, https://doi.org/10.1175/MWR-D-14-00086.1.
Wirth, V., M. Riemer, E. K. M. Chang, and O. Martius, 2018: Rossby wave packets on the midlatitude waveguide-A review. Mon. Wea. Rev., 146, 1965-2001, https://doi.org/10.1175/ MWR-D-16-0483.1.

Wolf, G., and V. Wirth, 2015: Implications of the semigeostrophic nature of Rossby waves for Rossby wave packet detection. Mon. Wea. Rev., 143, 26-38, https://doi.org/10.1175/MWR-D14-00120.1.

— , and — 2017: Diagnosing the horizontal propagation of Rossby wave packets along the midlatitude waveguide. Mon. Wea. Rev., 145, 3247-3264, https://doi.org/10.1175/MWR-D-16-0355.1.

Zimin, A. V., I. Szunyogh, B. R. Hunt, and E. Ott, 2006: Extracting envelopes of nonzonally propagating Rossby wave packets. Mon. Wea. Rev., 134, 1329-1333, https://doi.org/10.1175/ MWR3122.1. 